\title{
Desconcentração regional e diversificação da indústria no Estado do Rio de Janeiro - 2003/2014
}

\author{
Henrique Schmidt dos Reis Lacerda ${ }^{2}$ \\ João Saboia ${ }^{3}$
}

\section{RESUMO}

As mudanças sofridas pela indústria brasileira na última década e meia modificaram o parque industrial geograficamente e setorialmente. 0 estudo aqui desenvolvido cobre o período 2003/2014 e procura identificar a dinâmica industrial, analisando seus efeitos em termos da distribuição regional e setorial da indústria no estado do Rio de Janeiro. Utilizando dados da RAIS para as variáveis emprego, número de estabelecimentos, massa salarial e salário médio, o trabalho destaca as principais mudanças ocorridas no Rio de Janeiro. Uma de suas características é o papel do setor petroleiro, que se desenvolve rapidamente no período e transforma Macaé em um importante polo industrial do estado. 0 processo de desconcentração regional e diversificação setorial da indústria fluminense ocorre de forma heterogênea e o estudo busca identificá-lo destacando as principais microrregiões fluminenses.

PALAVRAS-CHAVE: Desconcentração regional, Diversificação setorial; Rio de Janeiro.

\section{ABSTRACT}

The changes observed in the Brazilian industry during the last decade and a half have modified the industrial park in regional and sectoral terms. This study intends to identify the dynamics of the industry in the period 2003/2014 analyzing its effects from the regional and sectorial point of view in the state of Rio de Janeiro. Using data from RAIS on variables such as employment, number of establishments, wage mass and average salary, the study points to the main changes occurred in Rio de Janeiro. One of its important characteristic is the petroleum sector, which developed rapidly in the period and transformed Macaé into an important industrial pole of the state. The process of regional deconcentration and sector diversification of the industry occurs heterogeneously and the study seeks to identify it highlighting the most important micro regions of Rio de Janeiro.

KEY-WORDS: Regional deconcentration; Sector diversification; Rio de Janeiro.

\section{Introdução}

A dinâmica industrial brasileira se modificou ao longo de sua história. Os movimentos industriais na década de 80 e 90 começaram a ser estudados, entre outros, por Diniz (1993) e Diniz e Crocco (1996). Os estudos de ambos os autores mostraram que a indústria paulista e fluminense perderam representatividade no período e que a dinâmica industrial não mais estava restrita às regiões metropolitanas das duas maiores cidades do país. A indústria passava a se concentrar em um polígono industrial que se estendia do interior do Rio Grande do Sul ao interior de Minas Gerais. Essa nova dinâmica da indústria nacional nas últimas décadas permitiu o desenvolvimento industrial nos estados do Sul e no interior mineiro. Montoya (2002) sinaliza que o Mercosul foi um dos indutores do movimento industrial do

1 Este artigo é uma versão reduzida de Lacerda (2017) e Lacerda e Saboia (2017) que tratam da indústria no Rio de Janeiro e no Brasil. Nesta versão é tratado apenas o caso do Rio de Janeiro. O trabalho contou com o apoio de bolsas do CNPq para os dois autores.

2 Mestrando do IE/UFRJ.

3 Professor emérito do IE/UFRJ. 
sul do país, região de integração com Argentina, Uruguai e Paraguai. O parque industrial buscava a proximidade dos parceiros internacionais e do mercado consumidor do Sudeste.

Uma visão diferente sobre o dinamismo industrial nas décadas de 80 e 90 foi abordada por Negri (1994), Pacheco (1999) e Saboia (2000). Os três autores argumentaram que o parque industrial não ficou preso ao polígono industrial, situado entre o Sudeste e o Sul do país. Negri (1994) mostrou que alguns setores industriais migraram para o Nordeste, zona franca de Manaus e interior da região Centro-Oeste. Os incentivos fiscais dados pelo governo federal, o desenvolvimento da indústria voltada à agricultura e a necessidade de menores custos de produção foram determinantes para o movimento industrial analisado pelo autor. Pacheco (1999) acreditava que a dinâmica industrial ocorreu por motivos setoriais, mas que esse movimento foi intenso nos anos 80 e perdeu força nos anos 90. Saboia (2000) analisou o comportamento da indústria nos anos 90 e concluiu que o processo de desconcentração industrial foi forte nas principais regiões metropolitanas do país e que a nova dinâmica de aglomeração permitiu que novos núcleos industriais se formassem nas mais variadas regiões do Brasil. Saboia (2001) mostra que o processo de desconcentração ocorreu e que, como Montoya (2002) sinalizou, a região Sul foi a mais beneficiada pelo deslocamento industrial. A indústria tradicional também se desconcentrou e se moveu para regiões com pequena diversidade industrial: Nordeste e Centro-Oeste.

Azevedo e Toneto Júnior (2001) estudaram o comportamento dos setores industriais na década de 90. As indústrias intensivas em mão de obra migraram para regiões com menos custos. A intensiva em recursos naturais se estabeleceu próxima aos seus insumos. Já a indústria de bens de capital começou a deixar o eixo Rio - São Paulo em busca do interior dos outros estados industrializados. Ramos e Ferreira (2005) mostram a diferença estrutural da indústria nas capitais e no interior. Os autores argumentam que as grandes regiões industriais perderam capacidade produtiva e esse movimento abriu novas oportunidades nos estados do Sul e Sudeste. Sinalizam que a guerra fiscal é um dos determinantes para a desconcentração industrial. Focalizando na questão do movimento da indústria para o Nordeste, Saboia (2004) mostrou as dificuldades de instalação da indústria nos estados nordestinos e salientou que o abismo produtivo entre as capitais da região e o interior continuava sendo um entrave para 0 desenvolvimento da indústria na região.

O estado de São Paulo foi e continua sendo o principal centro industrial do país, mas vem perdendo participação no total da indústria brasileira. Suzigan et al (2001) estudaram a heterogeneidade da indústria paulista e comparam o desempenho industrial no interior e na capital. Azzoni (2002) defende que o papel da região metropolitana de São Paulo continua sendo muito importante, se mantendo como principal centro industrial do país. Pereira e Lemos (2003) e Lemos et alii (2003) mostraram que a indústria nacional continuava concentrada em São Paulo e em seu entorno. Concordam que o surgimento de novos polos industriais ocorreu no país, mas afirmam que a influência dessas novas aglomerações é pequena se comparada com os polos tradicionais.

A decisão da localização das plantas industriais foi estudada por Oliveira Junior (2006). O autor concluiu que as características do setor industrial são determinantes para a escolha da localização da indústria. As características analisadas foram: custos salariais, economias de aglomeração, proximidade do mercado consumidor e as plantas já existentes. Ardissone (2009) faz uma análise das 58 microrregiões com maior valor de transformação industrial e conclui que o tipo da indústria é um forte determinante do grau de desconcentração do setor. Outro estudo sobre a desconcentração industrial é Saboia (2013), onde o autor mostra que o processo continuou ocorrendo até 2007. O movimento se deu em direção as regiões de menor participação na distribuição da indústria e foi generalizado entre diferentes setores industriais.

O tema foi debatido durante as últimas décadas a nível nacional, mas foram relativamente poucos os estudos sobre a dinâmica industrial fluminense. Marcelino, Brito e Cassiolato 
(2015) mostram que a indústria no estado do Rio de Janeiro teve bom desempenho no período 2000-2011, destacando-se o setor do petróleo que alavancou o setor industrial do estado. 0 estudo também mostrou que o Rio de Janeiro tem boa posição no ranking de P\&D nacional, tendo como determinante o setor petroleiro. Sobral (2012) analisou a periferia da região metropolitana do Rio de Janeiro entre 1995-2010 e concluiu que o forte ciclo de investimentos realizado no período foi descoordenado e que não existe uma estrutura que possibilite que o desenvolvimento regional possa dinamizar o parque industrial da região. $O$ artigo contesta a ideia de uma "inflexão econômica positiva" desde 1990 e mostra que existem indícios de uma desindustrialização relativa em curso.Silva (2009) buscou analisar a relação entre a dinâmica industrial e o desenvolvimento regional no estado do Rio de Janeiro. A conclusão do autor foi que a indústria fluminense teve forte crescimento entre 1990-2008, puxada principalmente pelo setor petroleiro, mas que os movimentos de descentralização mais interessantes e complexos foram oriundos da indústria de transformação. Sobral (2016) analisou a desindustrialização fluminense, discordando da ideia da "inflexão econômica positiva" do estado desde a década de 90. A criação de um "vácuo produtivo" na periferia da região metropolitana é um dos pilares do estudo. Já Medeiros Júnior (2013) apresentou em seu trabalho o dinamismo econômico do Norte Fluminense e Médio Paraíba. Esse desenvolvimento foi originado através de investimentos industriais, proporcionando a essas regiões melhoria no mercado de trabalho e consolidando-as como polos de desenvolvimento fluminense. Medeiros Júnior (2015) analisou o processo de concentração de renda entre as regiões do estado do Rio de Janeiro, mostrando que a distância entre as regiões mais ricas e as mais pobres aumentou na primeira década do século XXI. Egler, Dominguez e Regato (2015) desenvolveram um estudo voltado para a geografia regional fluminense, identificando as diferenças regionais e as possíveis políticas que poderiam suavizar as disparidades entre regiões.

O objetivo de nosso artigo é analisar o processo de desconcentração regional e a diversificação setorial da indústria de transformação e extrativa no estado do Rio de Janeiro.

A análise do período 2003-2014 busca identificar o comportamento industrial no período inicial de forte crescimento econômico do país e o pós-crise de 2008 com o arrefecimento da economia. Não são incluídos os anos pós-2014 quando a economia brasileira entrou em crise e na qual se encontra desde então. $O$ trabalho está dividido em duas seções, além desta introdução, e uma seção de considerações finais.

A próxima seção faz uma análise da indústria fluminense do ponto de vista da concentração regional, enquanto a seguinte analisa o tema da diversificação setorial. A separação da análise nos temas de concentração regional e diversificação setorial tem o objetivo de apresentar ao leitor a dinâmica industrial fluminense de forma ampla, identificando seu comportamento e transformações no período estudado. Para isso são apresentados dois cortes temporais 2003/2008 e 2008/2014.

Tendo em vista as limitações de tamanho do artigo, um conjunto de tabelas adicionais, incluindo dados municipais, não puderam ser incluídos no texto, podendo ser acessadas em Lacerda e Saboia (2017).

\section{0 processo de desconcentração regional da indústria no Rio de Janeiro}

Ao analisar todos os estados do país, o Rio de Janeiro se posicionou entre as seis unidades federativas de maior importância industrial. No volume de emprego e número de estabelecimentos, o estado se manteve na sexta posição durante o período analisado, enquanto que assumiu a primeira colocação em salário médio e a segunda posição na massa salarial paga na indústria. As variáveis analisadas seguem a tendência da indústria nacional, apresentando forte crescimento até 2008 e menores taxas de variação entre 2008 e 2014. 
Em valores absolutos, a indústria de transformação e extrativa fluminense cresceu $52 \%$ no número de empregos industriais, $149 \%$ na massa de salários, $30 \%$ no número de estabelecimentos industriais e $64 \%$ no salário médio pago. Mesmo com o período entre 2008-2014 apresentando menores taxas de crescimento, o resultado absoluto do desempenho industrial do estado do Rio de Janeiro foi expressivo.

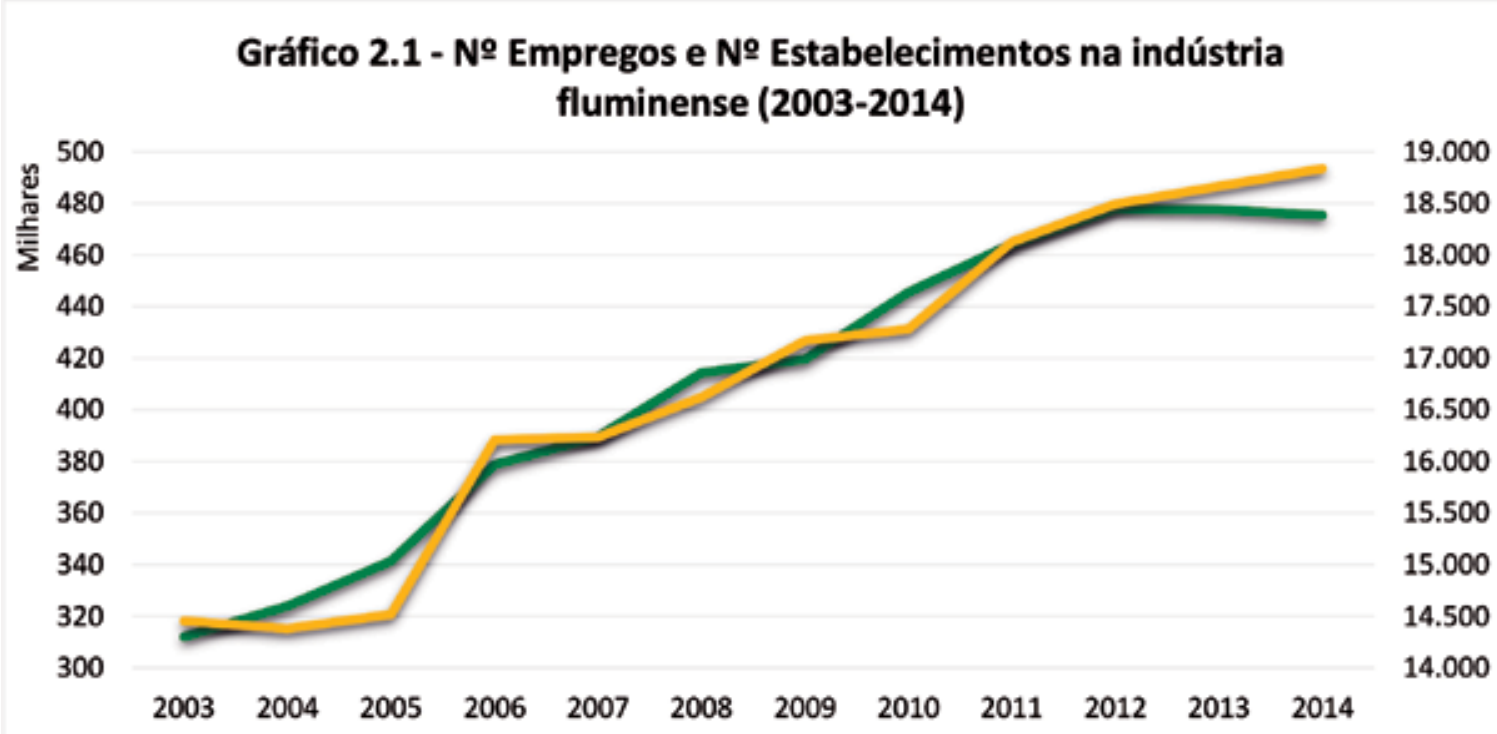

Fonte: Elaboração própria do autor (RAIS)

No Emprego $\quad$ N2 Estabelecimento

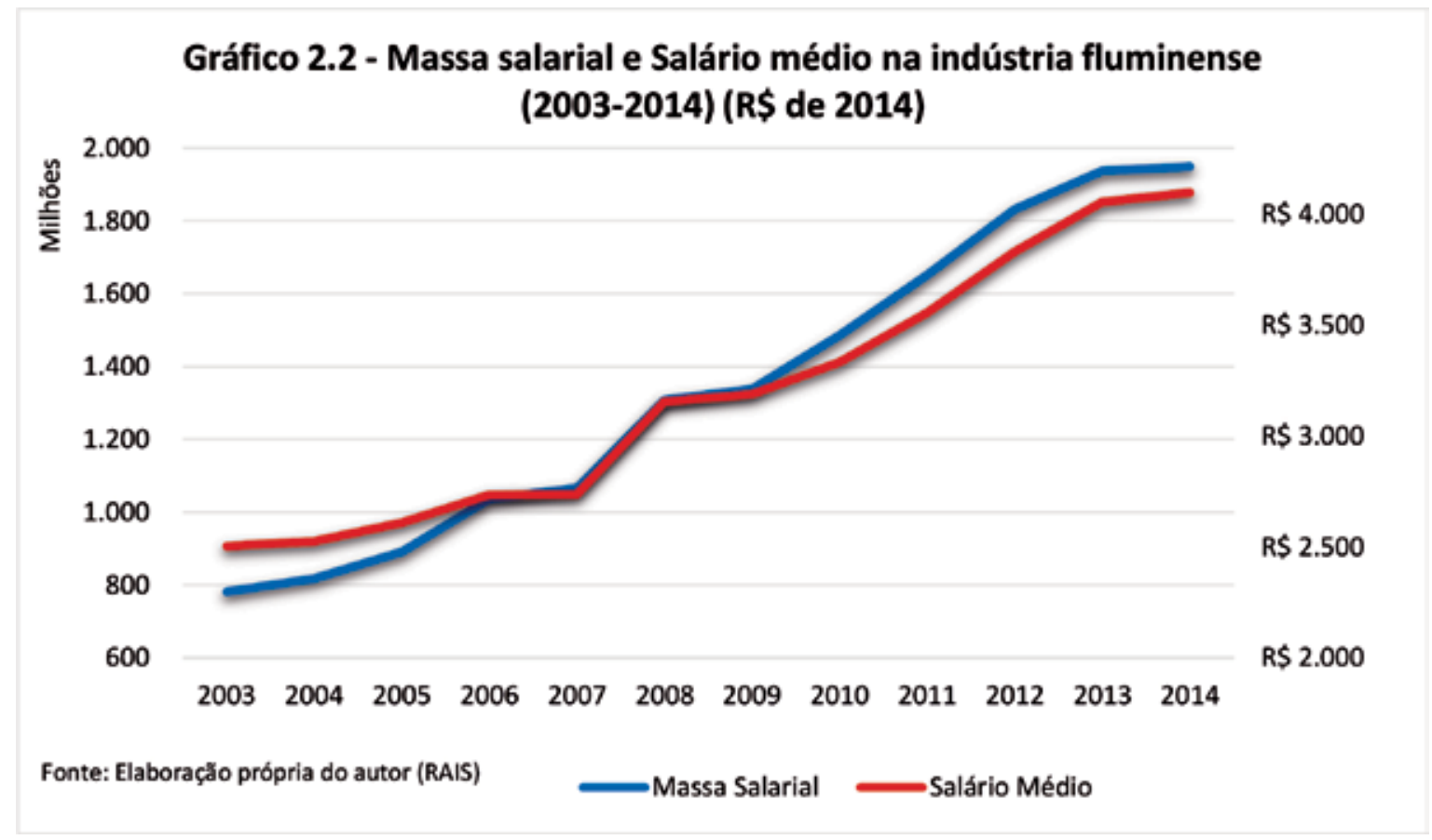

A indústria fluminense se diferencia do parque industrial nacional em duas variáveis. A massa salarial e o salário médio da indústria no Rio de Janeiro apresentaram taxas de crescimento superiores às observadas nas variáveis emprego e estabelecimentos industriais. Os dados mostram que o crescimento do setor petroleiro elevou de forma substancial a massa de salários paga no estado e consequentemente elevou o salário médio. A diferença entre o Rio de Janeiro e o estado de São Paulo na remuneração média aumentou no período analisado. Em 2003 o salário médio industrial no Rio de Janeiro era $5 \%$ maior do que o paulista e, em 2014 , esse valor passou a ser $42 \%$ maior. 
A microrregião do Rio de Janeiro responde em média por $60 \%$ do parque estadual. A indústria se concentra principalmente na região metropolitana da capital do estado, que, por sua vez, possui maior participação no Rio de Janeiro do que, por exemplo, o estado de São Paulo exerce no cenário nacional. Outro resultado importante é que a microrregião do Rio de Janeiro perde representatividade, enquanto o interior ganha a parcela perdida pela capital.

Apesar de possuir dezoito microrregiões, o estado apresenta um parque industrial concentrado em quatro microrregiões: Rio de Janeiro, Macaé, Vale do Paraíba Fluminense e Serrana; Estes são os principais polos industriais do estado. Cada uma das microrregiões citadas possui força em determinado setor, exceto o Rio de Janeiro, que detém um parque industrial bem diversificado na região metropolitana. O Vale do Paraíba Fluminense se destaca na indústria de metalurgia básica, a microrregião Serrana concentra a indústria de artigos de vestuário, enquanto a região de Macaé domina o setor de extração de petróleo.

Em todas as variáveis a microrregião do Rio de Janeiro perdeu participação na indústria. Como mencionado, o estado do Rio de Janeiro possui alguns polos industriais bem focalizados, mas grande parte das outras microrregiões do estado não possuem qualquer representatividade industrial.

Na variável empregos industriais duas microrregiões se destacam. Macaé e o Vale do Paraíba Fluminense aumentaram suas participações percentuais em relação ao número total de empregos na indústria. Macaé se destaca no setor extrativo de petróleo e fabricação de máquinas e equipamentos, se tornando uma das regiões do estado que mais se desenvolveram e cresceram no período. O Vale do Paraíba Fluminense concentra os setores de metalurgia básica e montagem e fabricação de veículos. A CSN em Volta Redonda é uma das mais importantes siderúrgicas do país e transforma a microrregião em um polo metalúrgico nacional. As indústrias automobilísticas se instalaram no Vale do Paraíba Fluminense e elevaram sua representatividade na indústria. A cidade de Porto Real se destaca no crescimento das montadoras de veículos no estado que, por consequência, alavancou a participação da cidade no número de empregos industriais.

\begin{tabular}{|l|c|c|c|c|c|c|}
\hline \multirow{2}{*}{ Tabela 2.1 - Distribuição percentual empregos industriais por microrregião - Rio de Janeiro (2003/2008/2014) } \\
\hline \multirow{2}{*}{ Microgiões } & $\mathbf{2 0 0 3}$ & $\mathbf{2 0 0 8}$ & $\mathbf{2 0 1 4}$ & Variação (p.p) & Variação (p.p) & Variação (p.p) \\
\cline { 5 - 8 } & & & & $\mathbf{2 0 0 3 / 2 0 0 8}$ & $\mathbf{2 0 0 8 / 2 0 1 4}$ & $\mathbf{2 0 0 3 / 2 0 1 4}$ \\
\hline Rio de Janeiro & 64,3 & 62,0 & 59,1 & $-2,3$ & $-2,8$ & $-5,1$ \\
\hline Vale do Paraiba Fluminense & 7,5 & 8,1 & 8,6 & 0,6 & 0,5 & 1,1 \\
\hline Macaé & 5,3 & 7,6 & 8,2 & 2,3 & 0,7 & 3,0 \\
\hline Serrana & 4,6 & 4,7 & 4,1 & 0,1 & $-0,6$ & $-0,5$ \\
\hline Nova Friburgo & 4,3 & 4,5 & 4,1 & 0,2 & $-0,4$ & $-0,2$ \\
\hline Campos dos Goytacazes & 2,7 & 2,4 & 2,3 & $-0,3$ & $-0,1$ & $-0,4$ \\
\hline Três Rios & 1,8 & 1,9 & 2,3 & 0,0 & 0,4 & 0,5 \\
\hline Barra do Piraí & 1,7 & 1,4 & 1,4 & $-0,2$ & 0,0 & $-0,2$ \\
\hline Lagos & 1,1 & 0,8 & 1,1 & $-0,3$ & 0,3 & 0,0 \\
\hline Baía da IIha Grande & 1,6 & 1,9 & 2,1 & 0,2 & 0,2 & 0,5 \\
\hline Itaperuna & 1,0 & 1,0 & 1,3 & 0,0 & 0,3 & 0,3 \\
\hline Macacu-Caceribu & 0,8 & 0,7 & 0,6 & $-0,1$ & $-0,1$ & $-0,2$ \\
\hline Santo Antônio de Pádua & 0,8 & 0,7 & 0,9 & $-0,1$ & 0,2 & 0,1 \\
\hline Itaguaí & 0,8 & 0,8 & 1,4 & $-0,1$ & 0,6 & 0,5 \\
\hline Cantagalo-Cordeiro & 0,5 & 0,7 & 0,7 & 0,2 & 0,0 & 0,1 \\
\hline Vassouras & 1,0 & 0,5 & 0,8 & $-0,4$ & 0,3 & $-0,1$ \\
\hline Bacia de São João & 0,2 & 0,3 & 0,9 & 0,1 & 0,6 & 0,7 \\
\hline Santa Maria Madalena & 0,0 & 0,0 & 0,1 & 0,0 & 0,0 & 0,0 \\
\hline Total & 100,0 & 100,0 & 100,0 & & & \\
\hline
\end{tabular}

Fonte: Elaboração própria do autor (RAIS) 
A massa salarial da indústria fluminense se concentra nas microrregiões do Rio de Janeiro e Macaé. O ganho de participação da região de Macaé no volume de salário pago na indústria pode ser explicado pela alta remuneração na indústria extrativa de petróleo. Outra microrregião que ganhou representatividade foi a Bacia de São João, guiada pela indústria de máquinas e equipamentos e também pela indústria do petróleo. As microrregiões do Rio de Janeiro e Vale do Paraíba Fluminense perdem participação no montante total da massa salarial, enquanto a microrregião de Macaé se transformou entre 2003 e 2014. O ganho de 6,2 pp na distribuição da variável mostra a força da economia petroleira no norte fluminense, salientando que o período entre 2003 e 2008 representa um ganho de 4,9 pp, enquanto entre 2008 e 2014 o crescimento foi bem menor, de apenas 1,4 pp.

\begin{tabular}{|l|c|c|c|c|c|c|}
\hline \multirow{2}{*}{ Tabela 2.2 - Distribuição percentual Massa Salarial da indústria por microrregião - Rio de Janeiro (2003/2008/2014) } \\
\hline & $\mathbf{2 0 0 3}$ & $\mathbf{2 0 0 8}$ & $\mathbf{2 0 1 4}$ & Variação (p.p) & Variação (p.p) & Variação (p.p) \\
\cline { 5 - 7 } & & & & $\mathbf{2 0 0 3 / 2 0 0 8}$ & $\mathbf{2 0 0 8 / 2 0 1 4}$ & $\mathbf{2 0 0 3 / 2 0 1 4}$ \\
\hline Rio de Janeiro & 63,8 & 62,3 & 60,7 & $-1,5$ & $-1,6$ & $-3,1$ \\
\hline Macaé & 16,0 & 20,8 & 22,2 & 4,9 & 1,4 & 6,2 \\
\hline Vale do Paraiba Fluminense & 8,8 & 7,1 & 5,6 & $-1,7$ & $-1,5$ & $-3,2$ \\
\hline Serrana & 2,3 & 2,1 & 1,8 & $-0,2$ & $-0,3$ & $-0,5$ \\
\hline Nova Friburgo & 1,7 & 1,3 & 1,2 & $-0,3$ & $-0,2$ & $-0,5$ \\
\hline Baía da Ilha Grande & 1,4 & 1,8 & 1,9 & 0,4 & 0,1 & 0,5 \\
\hline Campos dos Goytacazes & 1,1 & 0,8 & 0,9 & $-0,3$ & 0,1 & $-0,2$ \\
\hline Barra do Piraí & 0,9 & 0,6 & 0,5 & $-0,2$ & $-0,1$ & $-0,4$ \\
\hline Três Rios & 0,8 & 0,7 & 0,8 & $-0,1$ & 0,1 & 0,0 \\
\hline Itaguaí & 0,7 & 0,6 & 1,3 & $-0,2$ & 0,7 & 0,5 \\
\hline Lagos & 0,7 & 0,3 & 0,4 & $-0,4$ & 0,1 & $-0,3$ \\
\hline Itaperuna & 0,4 & 0,3 & 0,4 & $-0,1$ & 0,1 & 0,0 \\
\hline Vassouras & 0,4 & 0,1 & 0,2 & $-0,2$ & 0,1 & $-0,2$ \\
\hline Macacu-Caceribu & 0,4 & 0,3 & 0,2 & $-0,1$ & 0,0 & $-0,2$ \\
\hline Cantagalo-Cordeiro & 0,3 & 0,3 & 0,4 & 0,0 & 0,1 & 0,1 \\
\hline Santo Antônio de Pádua & 0,3 & 0,2 & 0,3 & 0,0 & 0,0 & 0,0 \\
\hline Bacia de São João & 0,1 & 0,2 & 1,3 & 0,1 & 1,1 & 1,2 \\
\hline Santa Maria Madalena & 0,0 & 0,0 & 0,0 & 0,0 & 0,0 & 0,0 \\
\hline Total & 100,0 & 100,0 & 100,0 & & & \\
\hline
\end{tabular}

Fonte: Elaboração própria do autor (RAIS)

A microrregião do Rio de Janeiro novamente perdeu participação quando considerado o número de estabelecimentos industriais, enquanto Nova Friburgo foi a única microrregião com crescimento significativo. A distribuição dos estabelecimentos industriais no Rio de Janeiro apresentou um fluxo mais equilibrado do que as demais variáveis por conta dos inúmeros estabelecimentos de pequeno porte localizados no interior. Enquanto a principal microrregião perdeu representatividade, a maior parte das demais regiões do estado ganharam algum espaço na distribuição de estabelecimentos.

\begin{tabular}{|c|c|c|c|c|c|c|}
\hline \multirow{2}{*}{ Microregiōes } & \multirow{2}{*}{2003} & \multirow{2}{*}{2008} & \multirow{2}{*}{2014} & Variação (p.p) & Variação (p.p) & Variação (p.p) \\
\hline & & & & $2003 / 2008$ & $2008 / 2014$ & $2003 / 2014$ \\
\hline Rio de Janeiro & 62,8 & 60,3 & 57,7 & $-2,5$ & $-2,6$ & $-5,1$ \\
\hline Nova Friburgo & 6,6 & 7,6 & 8,4 & 1,0 & 0,8 & 1,8 \\
\hline Serrana & 6,5 & 6,6 & 6,4 & 0,1 & $-0,2$ & $-0,2$ \\
\hline Vale do Paraiba Fluminense & 4,3 & 4,5 & 4,5 & 0,2 & 0,0 & 0,2 \\
\hline Campos dos Goytacazes & 3,7 & 3,8 & 3,7 & 0,1 & $-0,2$ & $-0,1$ \\
\hline Itaperuna & 2,4 & 2,2 & 2,5 & $-0,2$ & 0,3 & 0,1 \\
\hline Lagos & 2,2 & 2,3 & 2,8 & 0,0 & 0,5 & 0,6 \\
\hline
\end{tabular}


continuação Tabela 2.3

\begin{tabular}{|l|c|c|c|c|c|c|}
\hline Santo Antônio de Pádua & 1,8 & 1,9 & 2,1 & 0,0 & 0,2 & 0,3 \\
\hline Três Rios & 1,7 & 1,9 & 2,2 & 0,3 & 0,3 & 0,6 \\
\hline Barra do Piraí & 1,4 & 1,3 & 1,5 & $-0,1$ & 0,2 & 0,1 \\
\hline Macaé & 1,4 & 1,7 & 2,0 & 0,3 & 0,2 & 0,6 \\
\hline Vassouras & 1,1 & 0,9 & 0,9 & $-0,1$ & 0,0 & $-0,1$ \\
\hline Macacu-Caceribu & 1,0 & 1,0 & 1,0 & 0,1 & 0,0 & 0,0 \\
\hline Itaguaí & 1,0 & 1,1 & 1,2 & 0,1 & 0,1 & 0,2 \\
\hline Cantagalo-Cordeiro & 0,9 & 1,0 & 1,2 & 0,1 & 0,2 & 0,3 \\
\hline Bacia de São João & 0,6 & 0,8 & 1,0 & 0,2 & 0,2 & 0,4 \\
\hline Baía da IIha Grande & 0,5 & 0,8 & 0,8 & 0,3 & 0,0 & 0,3 \\
\hline Santa Maria Madalena & 0,1 & 0,2 & 0,1 & 0,0 & 0,0 & 0,0 \\
\hline Total & 100,0 & 100,0 & 100,0 & & & \\
\hline
\end{tabular}

Fonte: Elaboração própria do autor (RAIS)

A evolução do salário médio industrial no estado do Rio de Janeiro demonstra como o setor do petróleo é importante nessa variável. As microrregiões com os maiores salários e maiores taxas de crescimento sofrem influência direta do setor petroleiro no estado. Macaé apresenta salários industriais de R $\$ 11$ mil em 2014 e a Bacia de São João evolui de R\$ 891 para R 6 mil - um crescimento de $600 \%$ em uma década. A capital do estado se mantém entre os três melhores salários médios do estado, enquanto que o Vale do Paraíba caiu consideravelmente no ranking dos melhores salários da indústria fluminense, inclusive com perda real no valor médio.

\begin{tabular}{|l|c|c|c|c|c|c|}
\hline \multicolumn{2}{|c|}{ Tabela 2.4 - Salário Médio Industrial por microrregião - Rio de Janeiro (2003/2008/2013) R\$ de 201 } \\
\hline & $\mathbf{2 0 0 3}$ & $\mathbf{2 0 0 8}$ & $\mathbf{2 0 1 4}$ & Variação (\%) & Variação (\%) & Variação (\%) \\
\cline { 5 - 7 } & & & $\mathbf{2 0 0 3 / 2 0 0 8}$ & $\mathbf{2 0 0 8 / 2 0 1 4}$ & $\mathbf{2 0 0 3 / 2 0 1 4}$ \\
\hline Macaé & 7.596 & 8.674 & 11.058 & 14,2 & 27,5 & 45,6 \\
\hline Bacia de São João & 891 & 2.163 & 6.224 & 142,8 & 187,8 & 598,9 \\
\hline Rio de Janeiro & 2.485 & 3.173 & 4.206 & 27,7 & 32,5 & 69,2 \\
\hline Itaguaí & 2.204 & 2.340 & 3.891 & 6,2 & 66,3 & 76,6 \\
\hline Baía da Ilha Grande & 2.204 & 3.044 & 3.744 & 38,1 & 23,0 & 69,8 \\
\hline Vale do Paraiba Fluminense & 2.946 & 2.773 & 2.669 & $-5,9$ & $-3,8$ & $-9,4$ \\
\hline Cantagalo-Cordeiro & 1.384 & 1.376 & 2.179 & $-0,6$ & 58,4 & 57,5 \\
\hline Serrana & 1.242 & 1.418 & 1.789 & 14,2 & 26,2 & 44,1 \\
\hline Campos dos Goytacazes & 1.037 & 1.093 & 1.599 & 5,4 & 46,4 & 54,3 \\
\hline Barra do Piraí & 1.307 & 1.419 & 1.441 & 8,6 & 1,5 & 10,3 \\
\hline Macacu-Caceribu & 1.142 & 1.205 & 1.394 & 5,5 & 15,7 & 22,1 \\
\hline Lagos & 1.545 & 1.095 & 1.390 & $-29,1$ & 26,9 & $-10,0$ \\
\hline Três Rios & 1.068 & 1.114 & 1.389 & 4,3 & 24,7 & 30,0 \\
\hline Santo Antônio de Pádua & 818 & 969 & 1.223 & 18,4 & 26,2 & 49,4 \\
\hline Vassouras & 1.014 & 894 & 1.190 & $-11,9$ & 33,1 & 17,3 \\
\hline Itaperuna & 993 & 987 & 1.184 & $-0,6$ & 19,9 & 19,3 \\
\hline Nova Friburgo & 988 & 948 & 1.177 & $-4,0$ & 24,1 & 19,1 \\
\hline Santa Maria Madalena & 671 & 713 & 1.022 & 6,2 & 43,3 & 52,2 \\
\hline Total & 2.503 & 3.155 & 4.099 & 26,0 & 29,9 & 63,7 \\
\hline
\end{tabular}

Fonte: Elaboração própria do autor (RAIS)

Como foi feito na seção anterior, analisamos a concentração regional através do $\mathrm{HHI}$ e $\mathrm{CR}$, buscando identificar as movimentações no parque industrial fluminense e quais foram os resultados da dinâmica industrial do estado. O estado possui quatro importantes eixos industriais: Rio de Janeiro, Macaé, Vale do Paraíba Fluminense e região Serrana. Essas microrregiões se destacam de alguma forma nas variáveis estudadas, moldando o mapa da indústria do estado do Rio de Janeiro. 
O índice $\mathrm{HHI}$ para a variável número de empregos industriais diminuiu constantemente durante o período analisado. A redução de 0,427 para 0,370 no índice mostra que ocorreu desconcentração regional nos empregos. A análise da distribuição percentual da variável mostra que esse movimento da indústria para novos polos ocorreu devido, principalmente, à perda de participação da microrregião do Rio de Janeiro. O processo de desconcentração também ocorreu na variável estabelecimentos, mas com maior força entre 2008 e 2014. A principal microrregião do estado perdeu representatividade na distribuição estadual, abrindo espaço para o crescimento das microrregiões no interior. A massa salarial apresentou um resultado surpreendente ao compararmos com as duas outras variáveis analisadas. Durante o período estudado, o índice $\mathrm{HHI}$ teve sua dinâmica alterada e os resultados mostram uma estagnação do processo de desconcentração regional da massa de salários no estado. Entre 2003 e 2007, o índice teve tendência de queda, mas no ano de 2008 houve uma reversão no processo e os números voltaram ao patamar de 2003. O processo de desconcentração passa a ser muito fraco a partir de 2009 e se modifica lentamente nos anos seguintes. Como foi dito anteriormente, a indústria petroleira em Macaé tem forte influência nos dados da massa salarial. O ganho de participação na distribuição percentual do estado foi significativo no período.

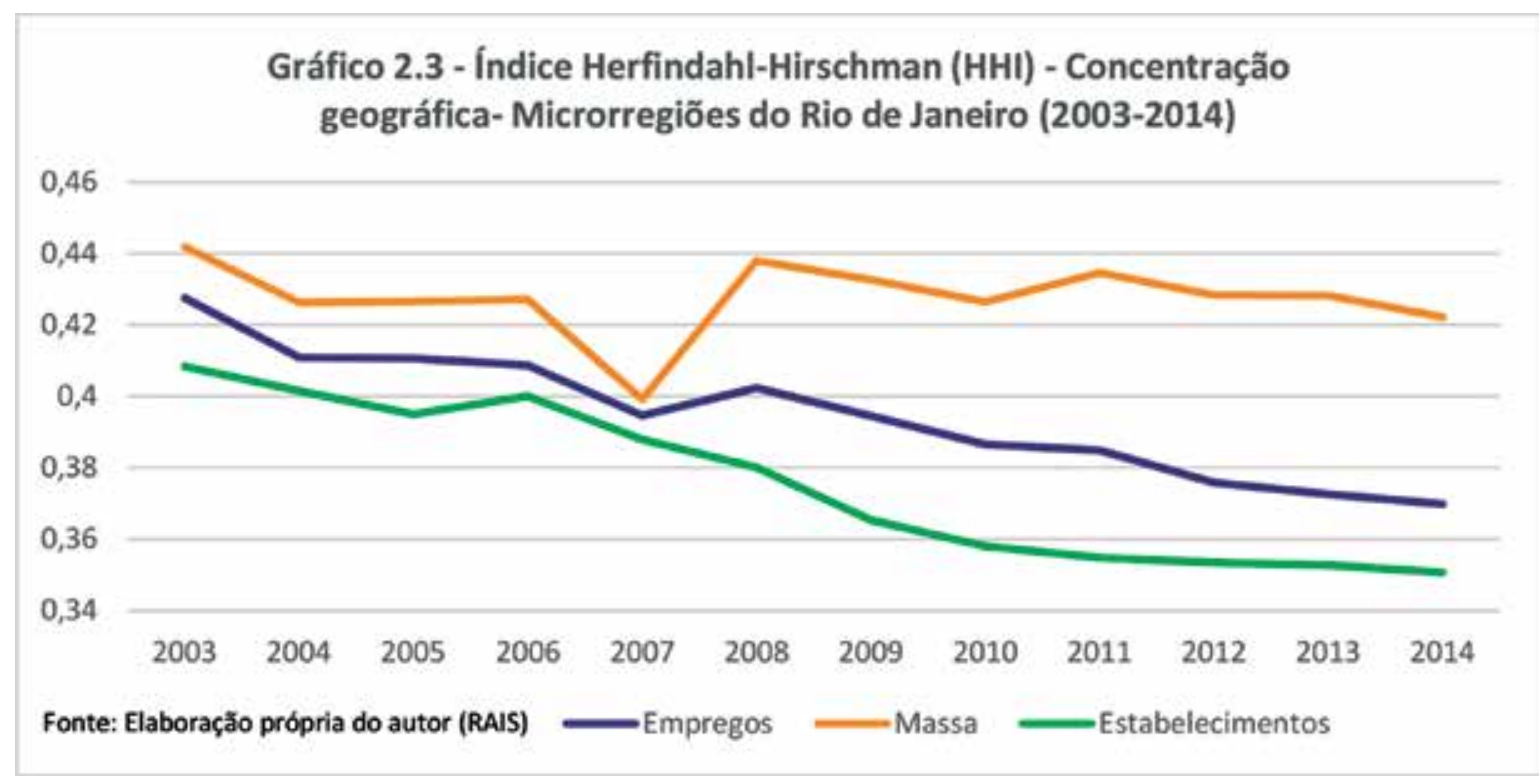

Além da análise do HHI, também utilizamos os CR (razão de concentração) já apresentados na seção anterior. A massa salarial apresenta as menores reduções nos $C R$, enquanto o número de empregos e de estabelecimentos mostram variações maiores. O volume de salários pagos na indústria fluminense se desconcentrou no CR-1, que simboliza a microrregião da capital do Rio de Janeiro, mas já no CR-2 observamos uma elevação da participação das duas principais microrregiões. O crescimento da microrregião de Macaé mais que compensa a perda de participação da microrregião da capital, elevando o CR-2 para $82,9 \%$ de toda a massa salarial do estado. Os CR-4 e CR-8 quase não se modificam no período, demonstrando que as principais regiões do estado mantiveram seus níveis de participação quando analisadas de forma agrupada.

O número de empregos continua concentrado na microrregião da capital, mas apresenta desconcentração nos CR-1 e CR-2. Quando agrupamos as quatro e oito microrregiões em número de empregos, observamos que a variável manteve o processo de desconcentração mesmo nos CR-4 e CR-8. O interior do estado ganhou participação no número de empregos e conseguiu reduzir todas as razões de concentração analisadas. A variável número de estabelecimentos seguiu a mesma dinâmica apresentada pelo número de empregos. A redução da concentração no estado foi desde o CR-1 até o CR-8. 
Os resultados mostram que o processo de desconcentração da indústria fluminense ocorreu em duas das três variáveis analisadas tanto através do $\mathrm{HHI}$ quanto dos $\mathrm{CR}$, mas é necessário salientar o quão altos esses números ainda são. As oito principais microrregiões do Rio de Janeiro concentram $96 \%$ de todo o salário pago no estado, $91 \%$ de todo o emprego e $88 \%$ de todos os estabelecimentos.

\begin{tabular}{|c|c|c|c|c|c|c|c|c|c|c|c|c|}
\hline \multirow{2}{*}{ Ano } & \multicolumn{4}{|c|}{ Massa Salarial } & \multicolumn{4}{|c|}{ № Empregos } & \multicolumn{4}{|c|}{ № Estabelecimentos } \\
\hline & CR-1 (\%) & CR-2 (\%) & CR-4 (\%) & CR-8 (\%) & CR-1 (\%) & CR-2 (\%) & CR-4 (\%) & CR-8 (\%) & CR-1 (\%) & CR-2 (\%) & CR-4 (\%) & CR-8 (\%) \\
\hline 2003 & 63,8 & 79,8 & 90,9 & 96,0 & 64,3 & 71,8 & 81,6 & 92,1 & 62,8 & 69,3 & 80,2 & 90,4 \\
\hline 2004 & 62,3 & 79,4 & 90,4 & 96,0 & 62,9 & 70,5 & 80,7 & 91,6 & 62,2 & 69,1 & 79,8 & 90,1 \\
\hline 2005 & 62,0 & 80,1 & 91,0 & 96,3 & 62,8 & 70,7 & 81,2 & 91,9 & 61,6 & 68,6 & 79,6 & 90,0 \\
\hline 2006 & 61,9 & 81,1 & 91,1 & 96,6 & 62,6 & 70,1 & 81,3 & 92,3 & 62,1 & 69,0 & 79,7 & 89,9 \\
\hline 2007 & 58,6 & 80,3 & 91,1 & 96,7 & 61,3 & 69,6 & 81,4 & 92,7 & 61,0 & 68,2 & 79,4 & 89,5 \\
\hline 2008 & 62,3 & 83,1 & 92,4 & 97,0 & 62,0 & 70,0 & 82,3 & 93,0 & 60,3 & 67,9 & 79,0 & 89,3 \\
\hline 2009 & 61,6 & 83,5 & 92,0 & 96,8 & 61,3 & 69,1 & 81,6 & 92,7 & 59,0 & 67,0 & 78,3 & 89,0 \\
\hline 2010 & 61,1 & 82,8 & 91,9 & 96,7 & 60,5 & 69,0 & 81,9 & 92,7 & 58,3 & 67,0 & 78,1 & 88,9 \\
\hline 2011 & 62,2 & 82,7 & 91,4 & 96,3 & 60,4 & 69,0 & 81,6 & 92,1 & 58,0 & 66,7 & 77,8 & 88,8 \\
\hline 2012 & 61,3 & 83,1 & 91,1 & 96,2 & 59,6 & 68,3 & 81,1 & 91,8 & 57,9 & 66,3 & 77,6 & 88,5 \\
\hline 2013 & 61,2 & 83,3 & 91,1 & 96,4 & 59,3 & 68,3 & 81,0 & 91,3 & 57,8 & 66,3 & 77,3 & 88,4 \\
\hline 2014 & 60,7 & 82,9 & 90,4 & 96,0 & 59,1 & 67,7 & 80,1 & 90,9 & 57,7 & 66,1 & 77,0 & 88,2 \\
\hline$(2003 / 2008 \mathrm{pp})$ & $-1,5$ & 3,4 & 1,5 & 1,0 & $-2,3$ & $-1,7$ & 0,7 & 0,9 & $-2,5$ & $-1,5$ & $-1,2$ & $-1,1$ \\
\hline$(2008 / 2014 \mathrm{pp})$ & $-1,6$ & $-0,2$ & $-2,0$ & $-1,1$ & $-2,8$ & $-2,3$ & $-2,3$ & $-2,1$ & $-2,6$ & $-1,8$ & $-2,0$ & $-1,1$ \\
\hline (2003/2014 pp) & $-3,1$ & 3,1 & $-0,5$ & 0,0 & $-5,1$ & $-4,0$ & $-1,5$ & $-1,2$ & $-5,1$ & $-3,3$ & $-3,2$ & $-2,2$ \\
\hline
\end{tabular}

Fonte: Elaboraçăo própria do autor (RAIS)

\section{A diversificação setorial da indústria no Rio de Janeiro}

A análise da distribuição espacial da indústria no estado do Rio de Janeiro é de grande importância no estudo, mas entender como os setores industriais estão distribuídos também ajuda a identificar o grau de complexidade das cadeias produtivas em cada uma das microrregiões do estado. Selecionaram-se os quinze principais setores e as microrregiões mais importantes do estado em relação a emprego, estabelecimentos e massa de salários industriais.

Inicialmente, vamos analisar os dados setoriais agregados do estado do Rio de Janeiro. Na variável empregos industriais os quatro principais setores perderam representatividade. A fabricação de produtos alimentícios, a confecção de artigos do vestuário, a fabricação de produtos químicos e a edição, impressão e reprodução de gravações perderam em média 2 pp entre 2003 e 2014. Mesmo assim, esses quatro setores citados se mantiveram no topo da distribuição percentual do número de empregos por setor.

Em contrapartida, outros três setores foram destaques positivos no período: fabricação de outros equipamentos de transporte (4,2 pp), extração de petróleo (3,8 pp) e fabricação de máquinas e equipamentos (2,7 pp).

\begin{tabular}{|c|c|c|c|c|c|c|}
\hline \multirow{2}{*}{ Setores } & \multirow{2}{*}{2003} & \multirow{2}{*}{2008} & \multirow{2}{*}{2014} & \multirow{2}{*}{\begin{tabular}{|l|} 
Variaş̃o (pp) \\
$2003 / 2008$ \\
\end{tabular}} & \multirow{2}{*}{\begin{tabular}{|l|} 
Variaş̆o $(\mathrm{pp})$ \\
$2008 / 2014$ \\
\end{tabular}} & \multirow{2}{*}{\begin{tabular}{|l|} 
Variaçāo (pp) \\
$2003 / 2014$ \\
\end{tabular}} \\
\hline & & & & & & \\
\hline 15:Fabr. Produtos Alimentícios & 14,0 & 13,1 & 11,4 & $-1,0$ & $-1,6$ & $-2,6$ \\
\hline 18:Confec. de Art. do Vestuário & 12,2 & 11,8 & 11,0 & $-0,4$ & $-0,8$ & $-1,2$ \\
\hline 24:Fabr. de Produtos Químicos & 9,8 & 7,9 & 7,2 & $-1,9$ & $-0,7$ & $-2,6$ \\
\hline 22:Edição, Impressão e Reprodução de Gravações & 6,7 & 5,5 & 4,7 & $-1,2$ & $-0,8$ & $-2,0$ \\
\hline 28:Fabr. de Produtos de Metal Exc. Máq. e Equip. & 6,3 & 6,8 & 6,6 & 0,6 & $-0,2$ & 0,3 \\
\hline 27:Metalurgia Básica & 5,8 & 5,2 & 5,3 & $-0,6$ & 0,1 & $-0,5$ \\
\hline 26:Fabr. de Produtos de Minerais Não-metálicos & 5,8 & 4,7 & 4,8 & $-1,1$ & 0,1 & $-1,0$ \\
\hline 25:Fabr. Art. de Borracha e Plást. & 5,2 & 5,5 & 5,8 & 0,2 & 0,3 & 0,6 \\
\hline 11:Extr. Petróleo e etc. & 4,8 & 9,3 & 8,6 & 4,5 & $-0,7$ & 3,8 \\
\hline 35:Fabr. de Outros Equip. Transp & 4,2 & 6,5 & 8,4 & 2,3 & 2,0 & 4,2 \\
\hline 29:Fabr. de Máquinas e Equip. & 3,8 & 5,8 & 6,5 & 2,0 & 0,7 & 2,7 \\
\hline 17:Fabr. de Produtos Têxteis & 3,6 & 2,1 & 1,6 & $-1,5$ & $-0,4$ & $-2,0$ \\
\hline 36:Fabr. de Móveis e Ind. Diversas & 3,3 & 2,7 & 3,0 & $-0,6$ & 0,3 & $-0,3$ \\
\hline 23:Fabr. de Coque, Refino Petróleo, Elabor. Comb. Nucl. e Prod Álcool & 2,6 & 1,2 & 4,0 & $-1,4$ & 2,8 & 1,4 \\
\hline 34:Fabr. e Montagem de Veículos Automotores, Reboques & 2,1 & 2,9 & 2,8 & 0,8 & $-0,1$ & 0,7 \\
\hline Demais Setores & 9,7 & 9,0 & 8,2 & $-0,7$ & $-0,8$ & $-1,5$ \\
\hline
\end{tabular}

Fonte: Elaboração própria do autor (RAIS) 
A variável com maior destaque na indústria fluminense foi a massa salarial, que retrata através da distribuição por setor uma forte concentração setorial. A extração de petróleo e o refino ganham juntos $18,2 \mathrm{pp}$, demonstrando a força do setor petroleiro sobre o volume de salários pagos. Em geral, os demais setores perderam participação na massa salarial. As exceções são a fabricação de outros equipamentos de transporte e a fabricação de máquinas e equipamentos com 2,9 pp e 1,6 pp, respectivamente.

\begin{tabular}{|c|c|c|c|c|c|c|c|}
\hline Tabela 2.7 - Distribuição percentual Massa Salarial da indústria por setor - Rio de Janeiro (2003/2008/2014) \\
\hline Setores & $\mathbf{2 0 0 3}$ & $\mathbf{2 0 0 8}$ & $\mathbf{2 0 1 4}$ & Variação (pp) & Variaçăo (pp) & Variação (pp) \\
\cline { 5 - 8 } & & & & $\mathbf{2 0 0 3 / 2 0 0 8}$ & $\mathbf{2 0 0 8 / 2 0 1 4}$ & $\mathbf{2 0 0 3 / 2 0 1 4}$ \\
\hline 11:Extr. Petróleo e etc. & 17,4 & 36,2 & 28,4 & 18,8 & $-7,8$ & 11,0 \\
\hline 23:Fabr. de Coque, Refino Petróleo, Elabor. Comb. Nucl. e Prod Álcool & 11,1 & 3,2 & 17,4 & $-7,9$ & 14,1 & 6,2 \\
\hline 35:Fabr. de Outros Equip. Transp & 4,3 & 5,9 & 7,2 & 1,6 & 1,3 & 2,9 \\
\hline 24:Fabr. de Produtos Químicos & 13,0 & 7,9 & 6,6 & $-5,1$ & $-1,3$ & $-6,4$ \\
\hline 29:Fabr. de Máquinas e Equip. & 4,4 & 6,3 & 6,0 & 1,9 & $-0,3$ & 1,6 \\
\hline 15:Fabr. Produtos Alimentícios & 8,3 & 5,8 & 4,7 & $-2,5$ & $-1,0$ & $-3,5$ \\
\hline 27:Metalurgia Básica & 7,2 & 5,5 & 4,0 & $-1,7$ & $-1,5$ & $-3,2$ \\
\hline 22:Edição, Impressão e Reprodução de Gravações & 6,6 & 4,6 & 3,7 & $-2,0$ & $-1,0$ & $-3,0$ \\
\hline 28:Fabr. de Produtos de Metal Exc. Máq. e Equip. & 4,3 & 4,0 & 3,5 & $-0,3$ & $-0,5$ & $-0,8$ \\
\hline 25:Fabr. Art. de Borracha e Plást. & 4,0 & 3,5 & 3,4 & $-0,5$ & 0,0 & $-0,5$ \\
\hline 18:Confec. de Art. do Vestuário & 4,0 & 3,2 & 3,3 & $-0,8$ & 0,1 & $-0,8$ \\
\hline 26:Fabr. de Produtos de Minerais Não-metálicos & 3,2 & 2,2 & 2,0 & $-1,0$ & $-0,2$ & $-1,1$ \\
\hline 34:Fabr. e Montagem de Veículos Automotores, Reboques & 2,1 & 2,4 & 2,0 & 0,3 & $-0,4$ & $-0,1$ \\
\hline 36:Fabr. de Móveis e Ind. Diversas & 1,5 & 1,1 & 1,1 & $-0,4$ & 0,1 & $-0,3$ \\
\hline 17:Fabr. de Produtos Têxteis & 1,7 & 0,8 & 0,6 & $-0,9$ & $-0,2$ & $-1,1$ \\
\hline Demais Setores & 7,0 & 7,5 & 6,1 & 0,4 & $-1,4$ & $-0,9$ \\
\hline
\end{tabular}

Fonte: Elaboração própria do autor (RAIS)

O número de estabelecimentos apresenta trajetória relativamente constante, com pequenas variações entre 2003 e 2014. O único destaque é a fabricação de máquinas e equipamentos com ganho de 3,4 pp. O salário médio por sua vez se destaca no setor petroleiro, com salários acima dos doze mil reais. O ganho real da remuneração média dos quinze principais setores foi de $30 \%$ no período.

\begin{tabular}{|c|c|c|c|c|c|c|c|}
\hline Tabela 2.8 - Distribuição percentual estabelecimentos industriais por setor - Rio de Janeiro (2003/2008/2014) \\
\hline Setores & $\mathbf{2 0 0 3}$ & $\mathbf{2 0 0 8}$ & $\mathbf{2 0 1 4}$ & Variação (pp) & Variação (pp) & Variação (pp) \\
\cline { 5 - 9 } & & & $\mathbf{2 0 0 3 / 2 0 0 8}$ & $\mathbf{2 0 0 8 / 2 0 1 4}$ & $\mathbf{2 0 0 3 / 2 0 1 4}$ \\
\hline 18:Confec. de Art. do Vestuário & 19,7 & 20,4 & 21,4 & 0,6 & 1,1 & 1,7 \\
\hline 15:Fabr. Produtos Alimentícios & 12,4 & 14,9 & 10,4 & 2,5 & $-4,5$ & $-2,0$ \\
\hline 28:Fabr. de Produtos de Metal Exc. Máq. e Equip. & 9,2 & 9,0 & 10,4 & $-0,3$ & 1,4 & 1,1 \\
\hline 22:Edição, Impressão e Reprodução de Gravaçães & 10,5 & 10,4 & 9,8 & 0,0 & $-0,6$ & $-0,7$ \\
\hline 26:Fabr. de Produtos de Minerais Não-metálicos & 8,1 & 6,9 & 7,1 & $-1,2$ & 0,2 & $-1,0$ \\
\hline 36:Fabr. de Móveis e Ind. Diversas & 7,0 & 5,4 & 6,8 & $-1,6$ & 1,4 & $-0,2$ \\
\hline 29:Fabr. de Máquinas e Equip. & 3,1 & 4,4 & 6,5 & 1,3 & 2,1 & 3,4 \\
\hline 25:Fabr. Art. de Borracha e Plást. & 4,4 & 4,6 & 3,9 & 0,1 & $-0,7$ & $-0,6$ \\
\hline 24:Fabr. de Produtos Químicos & 5,4 & 4,2 & 3,3 & $-1,2$ & $-0,9$ & $-2,1$ \\
\hline 17:Fabr. de Produtos Têxteis & 2,2 & 2,5 & 2,3 & 0,3 & $-0,2$ & 0,1 \\
\hline 35:Fabr. de Outros Equip. Transp & 1,2 & 1,4 & 2,0 & 0,2 & 0,6 & 0,8 \\
\hline 27:Metalurgia Básica & 2,4 & 1,8 & 1,4 & $-0,6$ & $-0,4$ & $-1,0$ \\
\hline 11:Extr. Petróleo e etc. & 1,2 & 1,1 & 1,2 & $-0,2$ & 0,2 & 0,0 \\
\hline Demais Setores & 0,6 & 0,9 & 1,1 & 0,3 & 0,2 & 0,5 \\
\hline 34:Fabr. e Montagem de Vé́culos Automotores, Reboques & 12,2 & 12,0 & 12,0 & $-0,3$ & 0,0 & $-0,2$ \\
\hline
\end{tabular}

Fonte: Elaboração própria do autor (RAIS)

$\mathrm{O}$ índice de concentração $\mathrm{HHI}$ apresenta movimentos distintos para as três variáveis estudadas. A massa salarial se concentrou, o número de empregos industriais sofreu redução e o índice do número de estabelecimentos industriais manteve-se constante. Esses dados tornam o resultado inconclusivo em relação à diversificação setorial do estado do Rio de Janeiro. 


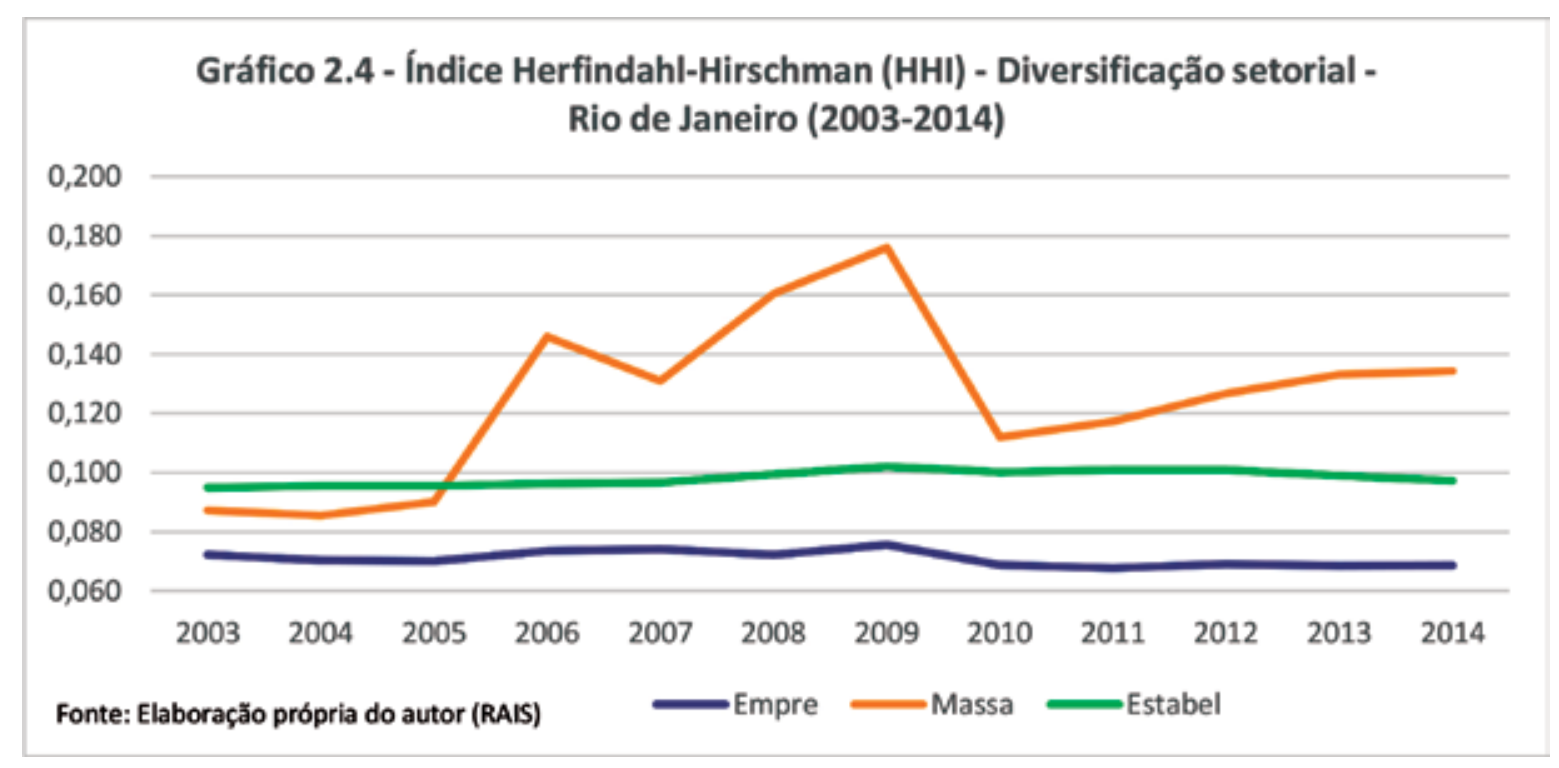

A microrregião do Rio de Janeiro, que engloba toda a região metropolitana da capital, é o principal polo industrial do estado como foi apresentado anteriormente. Sua complexidade econômica e industrial coloca essa microrregião como a mais diversificada do estado, contando com todos os setores estudados. Pela ótica dos empregos industriais, a ordem de distribuição dos principais setores não se alterou entre 2003 e 2014, mas os principais empregadores (Fabricação de produtos alimentícios, fabricação de produtos químicos e confecção de artigos do vestuário) perderam participação no período. Dentre os quinze principais setores dos empregos industriais da microrregião destacamos a fabricação de máquinas e equipamentos, que saltou de $4,5 \%$ para $6 \%$, fabricação de outros equipamentos de transporte, que aumentou de $3,7 \%$ para 9,4\%, e a fabricação de coque, refino petróleo, elaboração de combustíveis nucleares e produção de álcool, que saiu de 3,7\% do emprego em 2003 para 6,4\% em 2014. A maior parte dos outros setores mantiveram suas distribuições constantes ou perderam décimos na distribuição.

\begin{tabular}{|c|c|c|c|c|c|c|c|}
\hline Tabela 2.9 - Distribuição percentual empregos industriais por setor - Microrregião Rio de Janeiro (2003/2008/2014) \\
\hline Setores & \multirow{2}{*}{$\mathbf{2 0 0 3}$} & $\mathbf{2} 2008$ & $\mathbf{2 0 1 4}$ & Variação (pp) & Variaç̧̃o (pp) & Variaç̃o (pp) \\
\cline { 5 - 8 } & & & & & $\mathbf{2 0 0 3 / 2 0 0 8}$ & $\mathbf{2 0 0 8 / 2 0 1 4}$ & $\mathbf{2 0 0 3 / 2 0 1 4}$ \\
\hline 15:Fabr. Produtos Alimentícios & 14,5 & 13,5 & 11,9 & $-1,0$ & $-1,6$ & $-2,5$ \\
\hline 24:Fabr. de Produtos Químicos & 13,6 & 11,2 & 10,7 & $-2,4$ & $-0,4$ & $-2,9$ \\
\hline 18:Confec. de Art. do Vestuário & 11,9 & 10,7 & 10,5 & $-1,2$ & $-0,3$ & $-1,5$ \\
\hline 35:Fabr. de Outros Equip. Transp & 3,7 & 6,9 & 9,4 & 3,2 & 2,6 & 5,8 \\
\hline 22:Edição, Impressão e Reprodução de Gravações & 9,4 & 7,8 & 6,9 & $-1,6$ & $-0,9$ & $-2,5$ \\
\hline 25:Fabr. Art. de Borracha e Plást. & 3,7 & 1,5 & 6,4 & $-2,2$ & 4,9 & 2,8 \\
\hline 29:Fabr. de Máquinas e Equip. & 6,2 & 6,5 & 6,4 & 0,4 & $-0,2$ & 0,2 \\
\hline 23:Fabr. de Coque, Refino Petróleo, Elabor. Comb. Nucl. e Prod Álcool & 4,5 & 6,1 & 6,0 & 1,6 & $-0,1$ & 1,5 \\
\hline 26:Fabr. de Produtos de Metal Exc. Máq. e Equip. & 5,5 & 5,7 & 5,4 & 0,2 & $-0,4$ & $-0,2$ \\
\hline 36:Fabr. de Móveis e Ind. Diversas & 5,2 & 4,1 & 4,0 & $-1,1$ & $-0,1$ & $-1,2$ \\
\hline 27:Metalurgia Básica & 3,4 & 3,1 & 3,3 & $-0,4$ & 0,2 & $-0,2$ \\
\hline 21:Fabr. de Celulose e Papel & 2,6 & 2,8 & 2,8 & 0,2 & $-0,1$ & 0,2 \\
\hline 17:Fabr. de Produtos Têxteis & 2,0 & 2,2 & 1,9 & 0,2 & $-0,3$ & $-0,1$ \\
\hline Demais Setores & 2,1 & 1,6 & 1,6 & $-0,5$ & 0,0 & $-0,6$ \\
\hline 31:Fabr. de Máq, Aparelhos e Materiais Elétricos & 2,5 & 1,8 & 1,5 & $-0,7$ & $-0,3$ & $-1,0$ \\
\hline
\end{tabular}

Fonte: Elaboração própria do autor (RAIS)

A distribuição setorial da massa salarial apresenta dois importantes destaques. A fabricação de produtos químicos, que em 2003 era o principal setor na variável, perdeu 8,6 pp e foi ultrapassado pela fabricação de coque, refino petróleo, elaboração de combustíveis nucleares e produção de álcool, que ganhou 11,2 pp e representava em 2014 28,1\% dos salários pagos no setor industrial da microrregião do Rio de Janeiro. Houve importante 
perdas também para os segmentos de edição, impressão e reprodução de gravações, assim como na fabricação de produtos alimentícios. Tais mudanças refletem de certa forma as modificações apontadas na distribuição do emprego. Por outro lado, apontam também para as diferenças existentes entre os salários dos diversos setores da indústria. No caso da indústria de produtos alimentícios, por exemplo, sua participação em termos de salários é cerca da metade da participação no emprego. Já no refino do petróleo e setores correlatos é mais do que o quádruplo.

\begin{tabular}{|c|c|c|c|c|c|c|c|}
\hline Tabela 2.10 - Distribuição percentual da massa salarial por setor - Microrregião Rio de Janeiro (2003/2008/2014) \\
\hline Setores & $\mathbf{2 0 0 3}$ & $\mathbf{2 0 0 8}$ & $\mathbf{2 0 1 4}$ & Variação (pp) & Variação (pp) & Variação (pp) \\
\cline { 5 - 8 } & & & $\mathbf{2 0 0 3 / 2 0 0 8}$ & $\mathbf{2 0 0 8 / 2 0 1 4}$ & $\mathbf{2 0 0 3 / 2 0 1 4}$ \\
\hline 23:Fabr. de Coque, Refino Petróleo, Elabor. Comb. Nucl. e Prod Álcool & 16,9 & 4,7 & 28,1 & $-12,1$ & 23,3 & 11,2 \\
\hline 24:Fabr. de Produtos Químicos & 18,6 & 11,4 & 10,0 & $-7,2$ & $-1,4$ & $-8,6$ \\
\hline 35:Fabr. de Outros Equip. Transp & 3,9 & 5,9 & 7,4 & 2,1 & 1,5 & 3,6 \\
\hline 22:Edição, Impressão e Reprodução de Gravações & 9,9 & 7,0 & 5,7 & $-2,9$ & $-1,3$ & $-4,2$ \\
\hline 29:Fabr. de Máquinas e Equip. & 4,8 & 6,4 & 5,2 & 1,7 & $-1,2$ & 0,4 \\
\hline 15:Fabr. Produtos Alimentícios & 9,6 & 6,4 & 5,1 & $-3,2$ & $-1,3$ & $-4,5$ \\
\hline 25:Fabr. Art. de Borracha e Plást. & 5,0 & 4,4 & 3,9 & $-0,6$ & $-0,5$ & $-1,1$ \\
\hline 18:Confec. de Art. do Vestuário & 4,3 & 3,2 & 3,5 & $-1,2$ & 0,3 & $-0,8$ \\
\hline 27:Metalurgia Básica & 3,6 & 3,3 & 2,8 & $-0,3$ & $-0,5$ & $-0,8$ \\
\hline 28:Fabr. de Produtos de Metal Exc. Máq. e Equip. & 2,9 & 3,3 & 2,5 & 0,4 & $-0,8$ & $-0,5$ \\
\hline 26:Fabr. de Produtos de Minerais Não-metálicos & 3,4 & 2,3 & 1,9 & $-1,2$ & $-0,3$ & $-1,5$ \\
\hline 36:Fabr. de Móveis e Ind. Diversas & 1,7 & 1,3 & 1,3 & $-0,4$ & 0,0 & $-0,4$ \\
\hline 31:Fabr. de Máq, Aparelhos e Materiais Elétricos & 1,7 & 1,3 & 0,9 & $-0,4$ & $-0,3$ & $-0,7$ \\
\hline 21:Fabr. de Celulose e Papel & 1,2 & 0,9 & 0,9 & $-0,3$ & $-0,1$ & $-0,3$ \\
\hline 17:Fabr. de Produtos Têxteis & 1,1 & 0,7 & 0,5 & $-0,4$ & $-0,1$ & $-0,6$ \\
\hline Demais Setores & 11,4 & 37,6 & 20,3 & 26,2 & $-17,2$ & 9,0 \\
\hline
\end{tabular}

Fonte: Elaboração própria do autor (RAIS)

$\mathrm{Na}$ distribuição dos estabelecimentos industriais, o setor de confecção de artigos do vestuário se manteve em primeiro lugar no ranking geral. Dois setores perderam representatividade no período: metalurgia básica e fabricação de produtos químicos, enquanto que a fabricação de máquinas e equipamentos saiu de 3,8\% em 2003 para $8 \%$ em 2014.

\begin{tabular}{|c|c|c|c|c|c|c|c|}
\hline Tabela 2.11 - Distribuição percentual estabelecimentos industriais por setor - Microrregião Rio de Janeiro (2003/2008/2014) \\
\hline Setores & $\mathbf{2 0 0 3}$ & $\mathbf{2 0 0 8}$ & $\mathbf{2 0 1 4}$ & Variação (pp) & Variação (pp) & Variação (pp) \\
\cline { 5 - 8 } & & $\mathbf{2 0 0 3 / 2 0 0 8}$ & $\mathbf{2 0 0 8 / 2 0 1 4}$ & $\mathbf{2 0 0 3 / 2 0 1 4}$ \\
\hline 18:Confec. de Art. do Vestuário & 16,8 & 16,7 & 17,2 & $-0,1$ & 0,6 & 0,4 \\
\hline 22:Edição, Impressão e Reprodução de Gravações & 13,3 & 13,4 & 12,7 & 0,1 & $-0,7$ & $-0,6$ \\
\hline 28:Fabr. de Produtos de Metal Exc. Máq. e Equip. & 9,9 & 9,6 & 10,6 & $-0,3$ & 1,0 & 0,7 \\
\hline 15:Fabr. Produtos Alimentícios & 9,8 & 12,3 & 8,4 & 2,5 & $-3,9$ & $-1,4$ \\
\hline 29:Fabr. de Máquinas e Equip. & 3,8 & 5,3 & 8,0 & 1,5 & 2,7 & 4,2 \\
\hline 36:Fabr. de Móveis e Ind. Diversas & 7,3 & 5,8 & 7,3 & $-1,6$ & 1,6 & 0,0 \\
\hline 26:Fabr. de Produtos de Minerais Não-metálicos & 6,4 & 5,3 & 5,4 & $-1,2$ & 0,1 & $-1,0$ \\
\hline 24:Fabr. de Produtos Químicos & 7,5 & 5,9 & 4,7 & $-1,6$ & $-1,2$ & $-2,8$ \\
\hline 25:Fabr. Art. de Borracha e Plást. & 5,2 & 5,4 & 4,3 & 0,2 & $-1,1$ & $-0,9$ \\
\hline 35:Fabr. de Outros Equip. Transp & 1,5 & 1,9 & 2,7 & 0,4 & 0,8 & 1,2 \\
\hline 21:Fabr. de Máq, Aparelhos e Materiais Elétricos & 1,6 & 2,1 & 2,6 & 0,5 & 0,5 & 1,0 \\
\hline 21:Fabr. de Produtos Têxteis & 1,9 & 2,2 & 2,1 & 0,3 & $-0,1$ & 0,2 \\
\hline 27:Metalurgia Básicapel & 1,8 & 2,0 & 1,8 & 0,2 & $-0,1$ & 0,1 \\
\hline Demais Setores & 2,8 & 2,1 & 1,4 & $-0,7$ & $-0,7$ & $-1,4$ \\
\hline 23:Fabr. de Coque, Refino Petróleo, Elabor. Comb. Nucl. e Prod Álcool & 0,1 & 0,1 & 0,3 & 0,1 & 0,2 & 0,2 \\
\hline & 10,2 & 10,0 & 10,4 & $-0,3$ & 0,4 & 0,2 \\
\hline
\end{tabular}

Fonte: Elaboração própria do autor (RAIS)

O salário médio dos setores industriais na microrregião aumentou em média $33 \%$ e destaca-se novamente a fabricação de coque, refino petróleo, fabricação de coque, refino de petróleo, elaboração de combustíveis nucleares e produção de álcool que teve aumento real de $60 \%$ no período. A remuneração média no setor subiu de $R \$ 11.449$ 
em 2003 para $R \$ 18.319$ em 2014. O segundo setor nesta variável foi o de fabricação de produtos químicos com salário médio de R\$3.914em 2014.

A microrregião do Rio de Janeiro apresenta direções diferentes do HHI para cada variável analisada. O índice de concentração para a massa salarial teve forte aumento entre 2003 e 2014, puxado pelo setor de fabricação de coque, refino de petróleo, elaboração de combustíveis nucleares e produção de álcool. O índice para os empregos industriais sofreu queda devido à perda de participação de setores importantes citados acima. $\mathrm{O} \mathrm{HHI}$ para estabelecimentos se manteve relativamente estável durante o período.

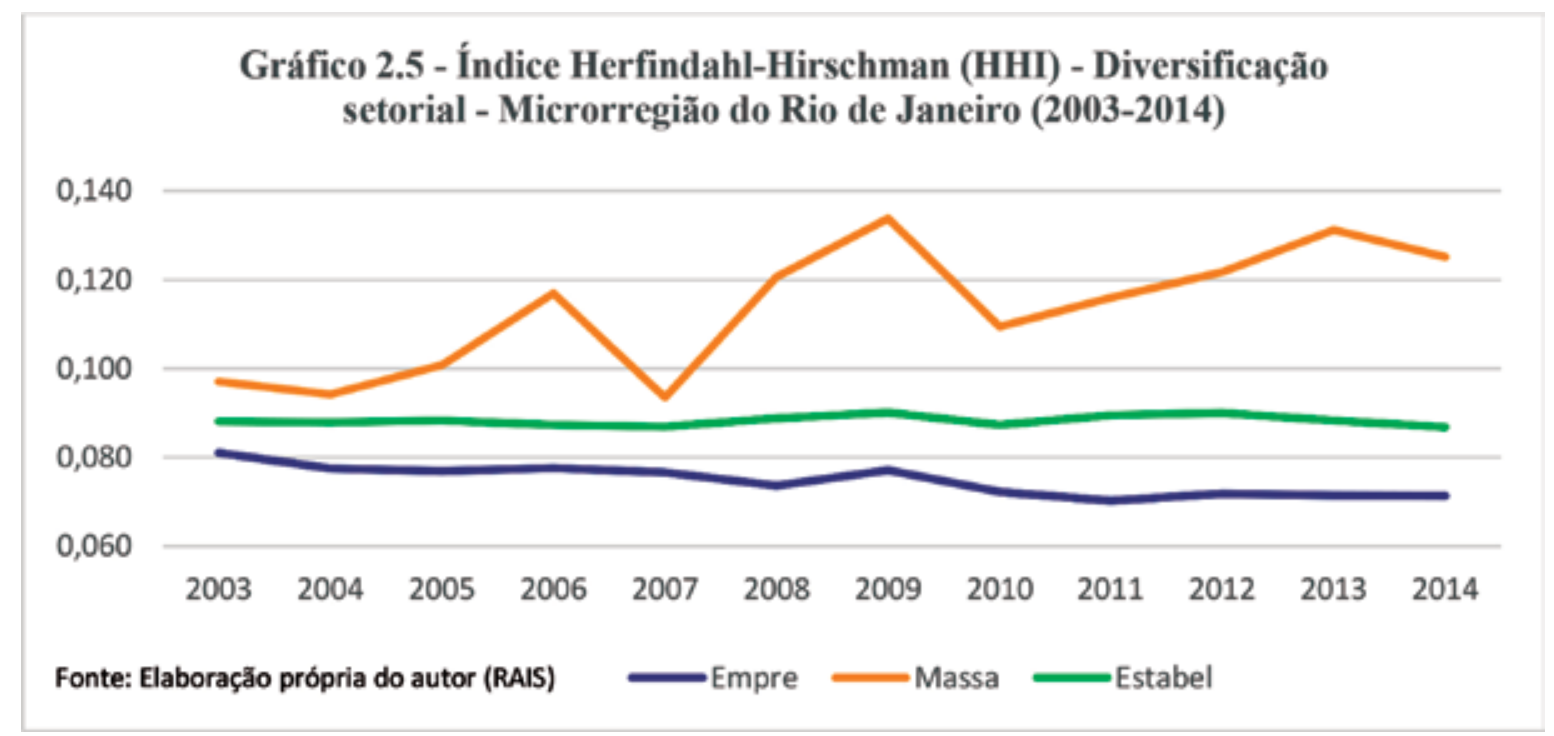

A segunda microrregião mais importante para a indústria é Macaé, que concentra grande parte do setor petroleiro no estado. Diferentemente da microrregião do Rio de Janeiro, Macaé é fortemente concentrada no setor de extração de petróleo e fabricação de maquinas e equipamentos. A distribuição setorial na variável empregos industriais mostra que 73,7\% dos empregos estavam no setor de extração de petróleo em 2014 e $16,3 \%$ na fabricação de máquinas e equipamentos. A soma desses dois setores representa $90 \%$ de todos os trabalhadores industriais da microrregião, enquanto que os $10 \%$ restantes estavam divididos nos restantes vinte e cinco setores.

\begin{tabular}{|c|c|c|c|c|c|c|}
\hline \multicolumn{2}{|c|}{ Tabela 2.12 - Distribuição percentual empregos industriais por setor - Microrregião de Macaé (2003/2008/2014) } \\
\hline Setores & $\mathbf{2}$ & \multirow{2}{*}{$\mathbf{2 0 0 3}$} & $\mathbf{2 0 1 4}$ & Variação (pp) & Variação (pp) & Variação (pp) \\
\cline { 4 - 7 } & & & $\mathbf{2 0 0 3 / 2 0 0 8}$ & $\mathbf{2 0 0 8 / 2 0 1 4}$ & $\mathbf{2 0 0 3 / 2 0 1 4}$ \\
\hline 11:Extr. Petróleo e etc. & 75,0 & 71,3 & 73,7 & $-3,7$ & 2,4 & $-1,3$ \\
\hline 29:Fabr. de Máquinas e Equip. & 10,2 & 17,0 & 16,3 & 6,8 & $-0,7$ & 6,1 \\
\hline 35:Fabr. de Outros Equip. Transp & 0,9 & 0,9 & 1,8 & 0,0 & 1,0 & 0,9 \\
\hline 28:Fabr. de Produtos de Metal Exc. Máq. e Equip. & 7,7 & 6,1 & 1,8 & $-1,7$ & $-4,3$ & $-5,9$ \\
\hline 25:Fabr. Art. de Borracha e Plást. & 0,1 & 0,2 & 1,1 & 0,0 & 0,9 & 0,9 \\
\hline 15:Fabr. Produtos Alimentícios & 1,3 & 1,4 & 0,9 & 0,0 & $-0,4$ & $-0,4$ \\
\hline 18:Confec. de Art. do Vestuário & 0,6 & 0,4 & 0,4 & $-0,2$ & 0,0 & $-0,2$ \\
\hline 36:Fabr. de Móveis e Ind. Diversas & 0,1 & 0,0 & 0,4 & $-0,1$ & 0,4 & 0,3 \\
\hline 14:Extr. Minerais Não-metálicos & 0,7 & 0,4 & 0,3 & $-0,3$ & 0,0 & $-0,3$ \\
\hline 22:Edição, Impressão e Reproduça de Gravaç̃̃es & 0,7 & 0,5 & 0,3 & $-0,2$ & $-0,2$ & $-0,4$ \\
\hline 26:Fabr. de Produtos de Minerais Não-metálicos & 0,7 & 0,2 & 0,2 & $-0,5$ & 0,0 & $-0,5$ \\
\hline 24:Fabr. de Produtos Químicos & 0,2 & 0,1 & 0,2 & $-0,1$ & 0,1 & 0,0 \\
\hline 37:Reciclagem & 0,4 & 0,1 & 0,1 & $-0,3$ & 0,0 & $-0,3$ \\
\hline 27:Metalurgia Básica & 0,4 & 0,8 & 0,0 & 0,4 & $-0,8$ & $-0,4$ \\
\hline Demais Setores & 0,9 & 0,0 & 0,0 & $-0,9$ & 0,0 & $-0,9$ \\
\hline
\end{tabular}

Fonte: Elaboração própria do autor (RAIS) 
A distribuição percentual da massa de salários é ainda mais impressionante, onde $88 \%$ da massa de salários em 2014 está concentrada no setor de extração de petróleo. 0 segundo setor melhor colocado é novamente o de máquinas e equipamentos com apenas 8,6\% no mesmo ano. Esses dois setores representam $96,5 \%$ de todo valor pago na indústria da microrregião de Macaé.

\begin{tabular}{|c|c|c|c|c|c|c|}
\hline \multicolumn{2}{|c|}{ Tabela 2.13 - Distribuição percentual massa salarial da indústria por setor - Microrregião de Macaé (2003/2008/2014) } \\
\hline Setores & $\mathbf{2 0 0 3}$ & $\mathbf{2 0 0 8}$ & $\mathbf{2 0 1 4}$ & Variação (pp) & Variação (pp) & Variação (pp) \\
\cline { 4 - 8 } & & & & $\mathbf{2 0 0 3 / 2 0 0 8}$ & $\mathbf{2 0 0 8 / 2 0 1 4}$ & $\mathbf{2 0 0 3 / 2 0 1 4}$ \\
\hline 11:Extr. Petróleo e etc. & 89,9 & 87,9 & 87,9 & $-2,0$ & 0,0 & $-2,0$ \\
\hline 29:Fabr. de Máquinas e Equip. & 6,7 & 8,7 & 8,6 & 2,0 & $-0,1$ & 1,9 \\
\hline 35:Fabr. de Outros Equip. Transp & 0,2 & 0,4 & 1,0 & 0,2 & 0,6 & 0,8 \\
\hline 25:Fabr. Art. de Borracha e Plást. & 0,0 & 0,1 & 0,9 & 0,0 & 0,8 & 0,8 \\
\hline 28:Fabr. de Produtos de Metal Exc. Máq. e Equip. & 2,1 & 1,9 & 0,4 & $-0,3$ & $-1,4$ & $-1,7$ \\
\hline 15:Fabr. Produtos Alimentícios & 0,2 & 0,2 & 0,1 & 0,0 & 0,0 & 0,0 \\
\hline 14:Extr. Minerais Não-metálicos & 0,1 & 0,1 & 0,1 & 0,0 & 0,0 & 0,0 \\
\hline 36:Fabr. de Móveis e Ind. Diversas & 0,0 & 0,0 & 0,0 & 0,0 & 0,0 & 0,0 \\
\hline 18:Confec. de Art. do Vestuário & 0,1 & 0,0 & 0,0 & 0,0 & 0,0 & 0,0 \\
\hline 22:Edição, Impressão e Reprodução de Gravações & 0,1 & 0,1 & 0,0 & 0,0 & 0,0 & 0,0 \\
\hline 24:Fabr. de Produtos Químicos & 0,1 & 0,0 & 0,0 & $-0,1$ & 0,0 & $-0,1$ \\
\hline 26:Fabr. de Produtos de Minerais Não-metálicos & 0,1 & 0,0 & 0,0 & $-0,1$ & 0,0 & $-0,1$ \\
\hline 20:Fabr. de Produtos de Madeira & 0,0 & 0,0 & 0,0 & 0,0 & 0,0 & 0,0 \\
\hline 37:Reciclagem & 0,1 & 0,1 & 0,0 & 0,1 & $-0,1$ & $-0,1$ \\
\hline 27:Metalurgia Básica & 0,3 & 0,0 & 0,0 & $-0,3$ & 0,0 & $-0,3$ \\
\hline Demais Setores & 0,0 & 0,5 & 0,8 & 0,5 & 0,3 & 0,8 \\
\hline
\end{tabular}

Fonte: Elaboração própria do autor (RAIS)

A distribuição percentual dos estabelecimentos industriais é mais equilibrada, mas se mantem concentrada no petróleo e máquinas e equipamentos, além da fabricação de produtos de metal (exclusive máquinas e equipamentos) e fabricação de produtos alimentícios. É importante salientar que o setor petroleiro se dividiu na extração e refino dentro do estado. Grande parte da exploração do petróleo tem como base Macaé, enquanto o refino ocorre na microrregião da capital. A cadeia produtiva que se forma no entorno do setor petroleiro explica a relação dos principais setores na microrregião de Macaé, ilustrada pela importância da fabricação de máquinas e equipamentos localmente.

Tabela 2.14 - Distribuição percentual estabelecimentos industriais por setor - Microrregião de Macaé (2003/2008/2014)

\begin{tabular}{|c|c|c|c|c|c|c|}
\hline \multirow{2}{*}{ Setores } & \multirow{2}{*}{2003} & \multirow{2}{*}{2008} & \multirow{2}{*}{2014} & Variação (pp) & Variação (pp) & Variação (pp) \\
\hline & & & & $2003 / 2008$ & $2008 / 2014$ & $2003 / 2014$ \\
\hline 11:Extr. Petróleo e etc. & 21,5 & 21,3 & 21,2 & $-0,2$ & $-0,1$ & $-0,3$ \\
\hline 28:Fabr. de Produtos de Metal Exc. Máq. e Equip. & 10,0 & 8,7 & 10,6 & $-1,3$ & 1,9 & 0,6 \\
\hline 15:Fabr. Produtos Alimentícios & 10,0 & 15,4 & 10,1 & 5,4 & $-5,3$ & 0,1 \\
\hline 22:Edição, Impressão e Reprodução de Gravações & 5,5 & 6,6 & 5,4 & 1,1 & $-1,2$ & $-0,1$ \\
\hline 26:Fabr. de Produtos de Minerais Não-metálicos & 6,0 & 3,5 & 4,1 & $-2,5$ & 0,6 & $-1,9$ \\
\hline 36:Fabr. de Móveis e Ind. Diversas & 2,0 & 0,7 & 3,3 & $-1,3$ & 2,6 & 1,3 \\
\hline 35:Fabr. de Outros Equip. Transp & 2,5 & 2,4 & 3,0 & $-0,1$ & 0,5 & 0,5 \\
\hline 14:Extr. Minerais Não-metálicos & 4,0 & 3,8 & 2,2 & $-0,2$ & $-1,7$ & $-1,8$ \\
\hline 37:Reciclagem & 1,0 & 1,4 & 0,5 & 0,4 & $-0,9$ & $-0,5$ \\
\hline 27:Metalurgia Básica & 2,0 & 0,3 & 0,3 & $-1,7$ & $-0,1$ & $-1,7$ \\
\hline Demais Setores & 5,0 & 6,3 & 7,6 & 1,3 & 1,3 & 2,6 \\
\hline
\end{tabular}

Fonte: Elaboração própria do autor (RAIS) 
Os melhores salários médios pagos também estão concentrados na exploração do petróleo e na fabricação de máquinas e equipamentos, com ganhos reais no período de $45 \%$ e $16 \%$, respectivamente. Importante destacar dois setores que obtiveram grandes ganhos salariais reais no período: a fabricação de artigos de borracha e plástico, que teve aumento de $726 \%$ entre 2003 e 2014, e a fabricação de outros equipamentos de transporte, que obteve ganho de $202 \%$ no mesmo período.

A microrregião de Macaé apresenta os maiores índices de concentração (HHI). Para a variável massa salarial, a microrregião apresenta altíssima taxa de concentração setorial da indústria - 0,780 em 2014. O HHI para os empregos industriais também é bastante alto e se contrapõe ao $\mathrm{HHI}$ dos estabelecimentos, que apresenta valores baixos. Tais dados confirmam que o setor petroleiro na região possui grande volume de empregos e massa de salários pagos.

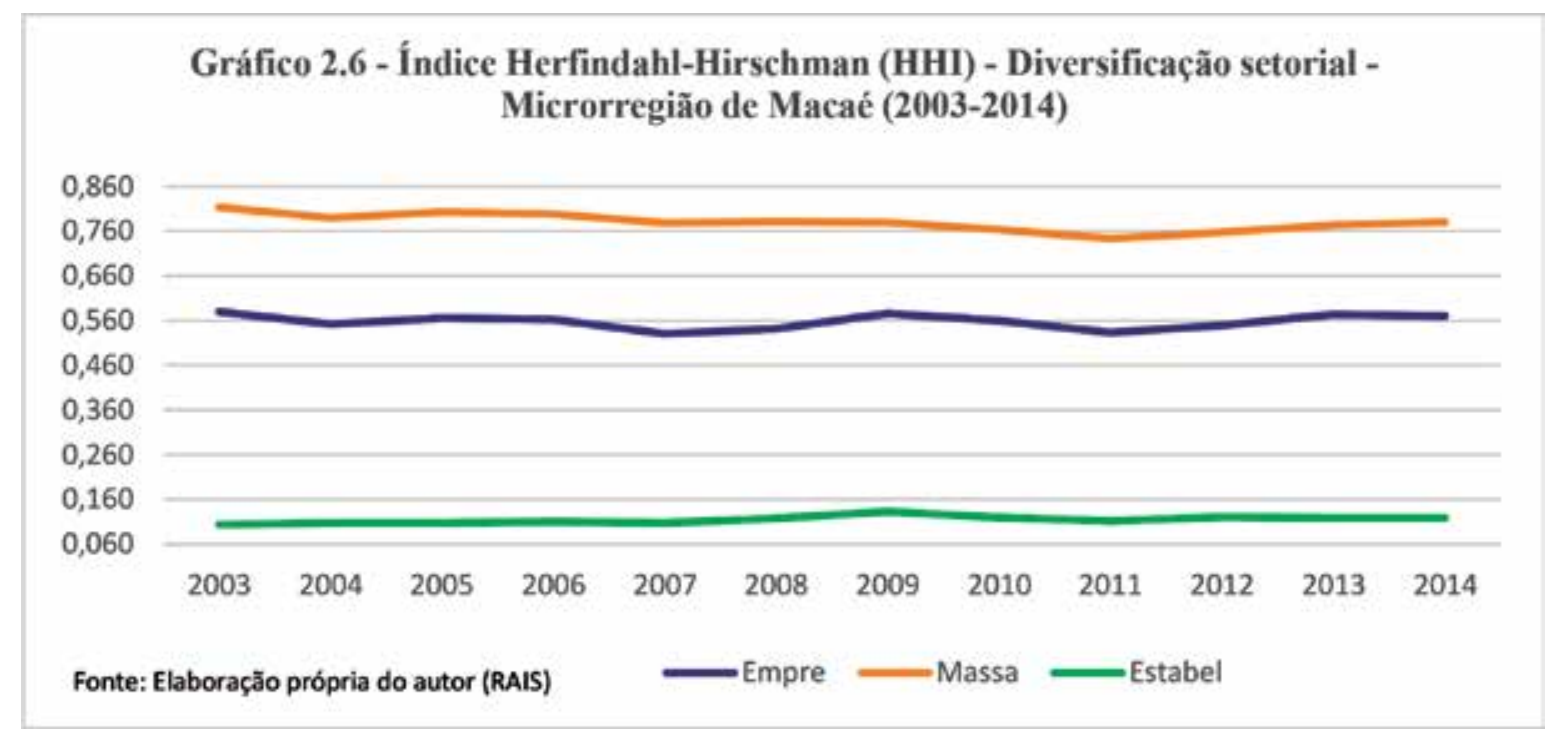

A terceira microrregião escolhida foi a do Vale do Paraíba Fluminense que historicamente se destacou pela metalurgia básica, sendo sede da CSN (Volta Redonda). A distribuição percentual do emprego continua tendo a metalurgia como principal setor, com aproximadamente $37 \%$ do emprego industrial da microrregião. Outros destaques são os setores de fabricação e montagem de veículos automotores e reboques, que subiu de 10,6\% em 2003 para 15,2\% em 2014, e a fabricação de máquinas e equipamentos, que ganhou 10 pp no período, representando atualmente o terceiro setor que mais emprega no Vale do Paraíba Fluminense.

\begin{tabular}{|c|c|c|c|c|c|c|}
\hline \multirow{2}{*}{ Setores } & \multirow{2}{*}{2003} & \multirow{2}{*}{2008} & \multirow{2}{*}{2014} & \multirow{2}{*}{\begin{tabular}{|c|} 
Variação (pp) \\
$2003 / 2008$ \\
\end{tabular}} & \multirow{2}{*}{\begin{tabular}{|l|} 
Variaçăo (pp) \\
$2008 / 2014$
\end{tabular}} & \multirow{2}{*}{\begin{tabular}{|l|} 
Variação (pp) \\
$2003 / 2014$ \\
\end{tabular}} \\
\hline & & & & & & \\
\hline 27:Metalurgia Básica & 40,1 & 33,4 & 37,2 & $-6,7$ & 3,7 & $-3,0$ \\
\hline 34:Fabr. e Montagem de Veículos Automotores, Reboques & 10,6 & 17,9 & 15,2 & 7,3 & $-2,7$ & 4,6 \\
\hline 29:Fabr. de Máquinas e Equip. & 1,1 & 3,1 & 11,2 & 2,0 & 8,1 & 10,1 \\
\hline 28:Fabr. de Produtos de Metal Exc. Máq. e Equip. & 10,2 & 11,2 & 8,6 & 1,0 & $-2,6$ & $-1,6$ \\
\hline 15:Fabr. Produtos Alimentícios & 10,6 & 8,5 & 8,0 & $-2,1$ & $-0,6$ & $-2,6$ \\
\hline 25:Fabr. Art. de Borracha e Plást. & 4,4 & 4,7 & 6,1 & 0,3 & 1,4 & 1,7 \\
\hline 26:Fabr. de Produtos de Minerais Não-metálicos & 5,6 & 4,4 & 3,9 & $-1,2$ & $-0,5$ & $-1,7$ \\
\hline 24:Fabr. de Produtos Químicos & 4,1 & 4,4 & 2,8 & 0,4 & $-1,7$ & $-1,3$ \\
\hline 23:Fabr. de Coque, Refino Petróleo, Elabor. Comb. Nucl. e Prod Álcool & 2,0 & 1,6 & 1,9 & $-0,4$ & 0,3 & $-0,1$ \\
\hline $\begin{array}{l}37: \text { Reciclagem } \\
\end{array}$ & 2,2 & 2,1 & 1,5 & $-0,1$ & $-0,5$ & $-0,6$ \\
\hline 22:Edição, Impressão e Reprodução de Gravações & 1,2 & 0,9 & 1,2 & $-0,3$ & 0,4 & 0,0 \\
\hline 36:Fabr. de Móveis e Ind. Diversas & 1,1 & 0,9 & 1,1 & $-0,2$ & 0,2 & 0,0 \\
\hline 18:Confec. de Art. do Vestuário & 1,0 & 0,7 & 1,0 & $-0,3$ & 0,3 & 0,0 \\
\hline 14:Extr. Minerais Não-metálicos & 0,8 & 0,3 & 0,6 & $-0,4$ & 0,3 & $-0,2$ \\
\hline 30:Fabr. de Máq. para Escritório e Equip. de Informática & 2,8 & 0,5 & 0,1 & $-2,3$ & $-0,4$ & $-2,7$ \\
\hline Demais Setores & 2,4 & 5,5 & $-0,5$ & 3,1 & $-5,9$ & $-2,8$ \\
\hline
\end{tabular}


Os reflexos das mudanças no emprego podem ser vistos na distribuição da massa de salários na microrregião. A metalurgia básica perdeu 12,9 pp, enquanto a fabricação e montagem de veículos automotores e reboques ganhou 5,6 pp e a fabricação de máquinas e equipamentos, 6,6 pp. Esses três setores foram os principais destaques no período. A política de isenção fiscal do estado do Rio de Janeiro para atrair montadoras de veículos levou à instalação de plantas industriais de sua cadeia na região do Vale do Paraíba Fluminense.

\begin{tabular}{|c|c|c|c|c|c|c|}
\hline \multirow{2}{*}{ Setores } & \multirow{2}{*}{2003} & \multirow{2}{*}{2008} & \multirow{2}{*}{2014} & \multirow{2}{*}{\begin{tabular}{|l} 
Variação (pp) \\
$2003 / 2008$ \\
\end{tabular}} & \multirow{2}{*}{\begin{tabular}{|l|} 
Variaçăo (pp) \\
$2008 / 2014$
\end{tabular}} & \multirow{2}{*}{\begin{tabular}{|l|l|} 
Variação (pp) \\
$2003 / 2014$ \\
\end{tabular}} \\
\hline & & & & & & \\
\hline 27:Metalurgia Básica & 51,6 & 42,6 & 38,8 & $-9,1$ & $-3,8$ & $-12,9$ \\
\hline 34:Fabr. e Montagem de Veículos Automotores, Reboques & 13,3 & 20,4 & 18,8 & 7,1 & $-1,6$ & 5,6 \\
\hline 29:Fabr. de Máquinas e Equip. & 0,6 & 2,3 & 7,3 & 1,7 & 5,0 & 6,6 \\
\hline 28:Fabr. de Produtos de Metal Exc. Máq. e Equip. & 7,2 & 7,0 & 5,6 & $-0,2$ & $-1,4$ & $-1,7$ \\
\hline 25:Fabr. Art. de Borracha e Plást. & 3,8 & 4,2 & 5,5 & 0,5 & 1,3 & 1,7 \\
\hline 23:Fabr. de Coque, Refino Petróleo, Elabor. Comb. Nucl. e Prod Álcool & 3,6 & 3,5 & 5,4 & $-0,1$ & 1,9 & 1,8 \\
\hline 15:Fabr. Produtos Alimentícios & 4,8 & 4,4 & 5,2 & $-0,3$ & 0,8 & 0,4 \\
\hline 24:Fabr. de Produtos Químicos & 5,5 & 6,1 & 4,1 & 0,6 & $-2,0$ & $-1,4$ \\
\hline 26:Fabr. de Produtos de Minerais Não-metálicos & 3,4 & 3,3 & 3,3 & $-0,1$ & 0,0 & $-0,1$ \\
\hline 37:Reciclagem & 1,2 & 1,0 & 1,0 & $-0,2$ & 0,0 & $-0,1$ \\
\hline 22:Edição, Impressão e Reprodução de Gravações & 0,4 & 0,3 & 0,7 & $-0,1$ & 0,3 & 0,2 \\
\hline 36:Fabr. de Móveis e Ind. Diversas & 0,3 & 0,3 & 0,5 & 0,0 & 0,2 & 0,2 \\
\hline 18:Confec. de Art. do Vestuário & 0,2 & 0,2 & 0,4 & 0,0 & 0,2 & 0,2 \\
\hline 14:Extr. Minerais Não-metálicos & 0,3 & 0,2 & 0,4 & $-0,1$ & 0,2 & 0,1 \\
\hline 30:Fabr. de Máq. para Escritório e Equip. de Informática & 2,6 & 0,2 & 0,1 & $-2,3$ & $-0,1$ & $-2,5$ \\
\hline Demais Setores & 1,2 & 3,9 & 3,0 & 2,8 & $-0,9$ & 1,9 \\
\hline
\end{tabular}

Ocorreram duas mudanças significativas na distribuição percentual do número de estabelecimentos industriais da microrregião. O setor de fabricação de produtos alimentícios perdeu posição, com redução de 7,2 pp no período estudado. O outro destaque foi o aumento da participação do setor de fabricação de máquinas e equipamentos, que saltou de 2,6\% dos estabelecimentos industriais em 2003 para 9,5\% em 2014.

\begin{tabular}{|c|c|c|c|c|c|c|}
\hline \multirow{2}{*}{ Setores } & \multirow{2}{*}{2003} & \multirow{2}{*}{2008} & \multirow{2}{*}{2014} & \multirow{2}{*}{\begin{tabular}{|l|} 
Variação (pp) \\
$2003 / 2008$ \\
\end{tabular}} & \multirow{2}{*}{\begin{tabular}{|l|} 
Variação (pp) \\
$2008 / 2014$
\end{tabular}} & \multirow{2}{*}{\begin{tabular}{|l|} 
Variação (pp) \\
$2003 / 2014$ \\
\end{tabular}} \\
\hline & & & & & & \\
\hline 28:Fabr. de Produtos de Metal Exc. Máq. e Equip. & 18,1 & 18,8 & 18,8 & 0,7 & 0,0 & 0,7 \\
\hline 15:Fabr. Produtos Alimentícios & 19,1 & 21,6 & 11,9 & 2,5 & $-9,8$ & $-7,2$ \\
\hline 29:Fabr. de Máquinas e Equip. & 2,6 & 5,6 & 9,5 & 3,0 & 3,9 & 6,9 \\
\hline 26:Fabr. de Produtos de Minerais Não-metálicos & 10,4 & 8,1 & 8,3 & $-2,3$ & 0,2 & $-2,1$ \\
\hline 36:Fabr. de Móveis e Ind. Diversas & 7,2 & 5,1 & 6,7 & $-2,1$ & 1,6 & $-0,5$ \\
\hline 25:Fabr. Art. de Borracha e Plást. & 4,0 & 4,3 & 4,8 & 0,3 & 0,5 & 0,8 \\
\hline 34:Fabr. e Montagem de Veículos Automotores, Reboques & 3,0 & 2,7 & 4,5 & $-0,4$ & 1,8 & 1,4 \\
\hline 24:Fabr. de Produtos Químicos & 3,7 & 3,6 & 3,1 & $-0,1$ & $-0,5$ & $-0,6$ \\
\hline 27:Metalurgia Básica & 2,9 & 2,7 & 2,8 & $-0,2$ & 0,1 & $-0,1$ \\
\hline 23:Fabr. de Coque, Refino Petróleo, Elabor. Comb. Nucl. e Prod Álcool & 0,2 & 0,3 & 0,4 & 0,1 & 0,1 & 0,2 \\
\hline Demais Setores & 5,6 & 7,9 & 8,7 & 2,3 & 0,8 & 3,1 \\
\hline
\end{tabular}

O salário médio manteve sua distribuição de 2003, onde quatro setores (fabricação de coque e refino de petróleo, fabricação de produtos químicos, metalurgia básica e fabricação e montagem de veículos automotores e reboques) dominam as primeiras posições com as melhores remunerações. O destaque negativo foi a metalurgia básica, que apresentou perda real no salário de 23,5\% entre 2003 e 2014.

A microrregião do Vale do Paraíba Fluminense, antes conhecida por sua especialização no setor de metalurgia básica, apresentou redução do HHI em duas das três variáveis estudadas. Os índices de concentração para massa salarial e estabelecimentos foram 
influenciados pela queda na representatividade da metalurgia básica e fabricação de produtos alimentícios, respectivamente. A variável de empregos industriais apresentou queda e depois elevação do índice. Esse movimento pode ser explicado também pelo crescimento do setor de fabricação e montagem de veículos automotores, reboques e fabricação de máquinas e equipamentos. Esse comportamento do índice de concentração dos empregos mostra que, apesar do setor de metalurgia ter perdido representatividade na variável, outros segmentos industriais cresceram e aumentaram a concentração nos principais setores da microrregião.

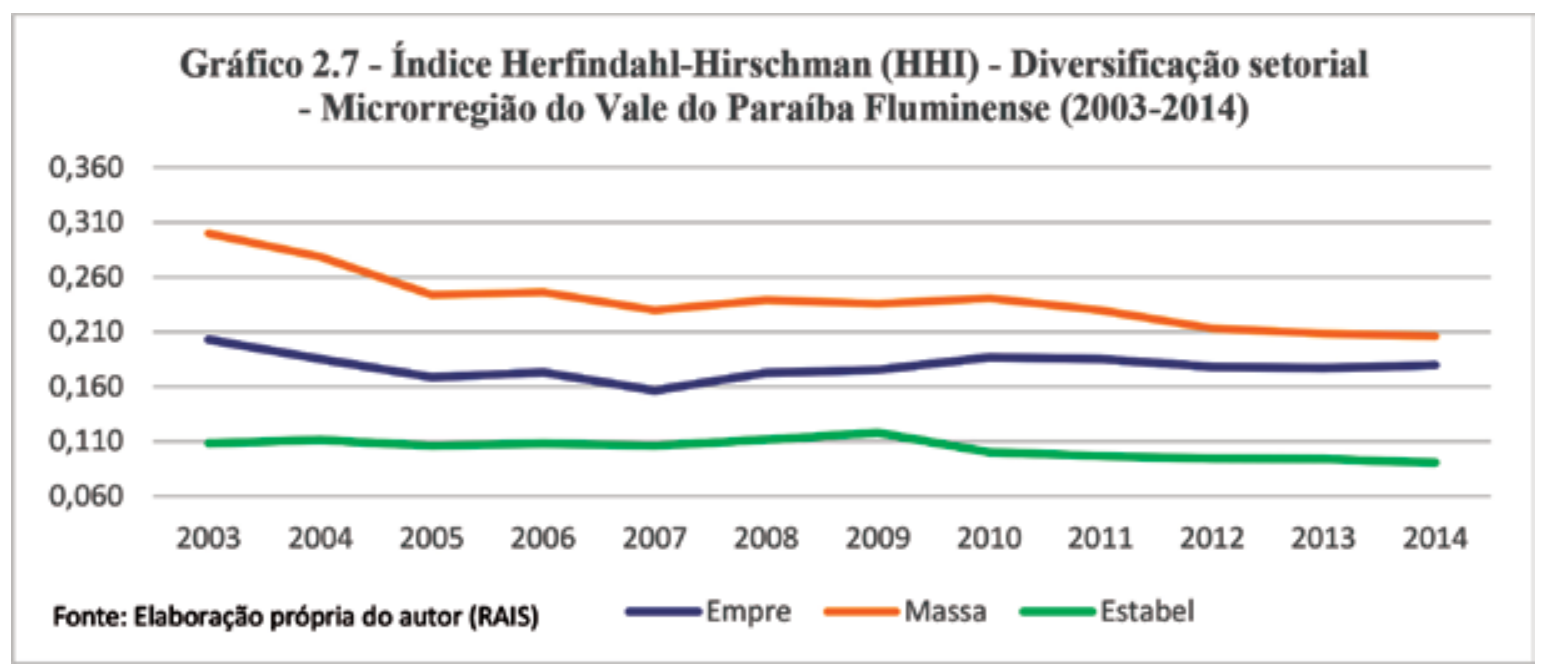

A quarta microrregião estudada foi a Serrana, que engloba Petrópolis e Teresópolis, duas cidades importantes no estado do Rio de Janeiro. Essa microrregião é conhecida pelo setor de confecções, vestuário e alimentício, sendo um dos maiores polos do estado. Os setores de confecção de artigos do vestuário e fabricação de produtos têxteis apresentam posições de destaque em todas as variáveis analisadas para a microrregião Serrana. A distribuição percentual do emprego industrial se concentra no setor têxtil, produtos alimentícios e móveis. Durante o período estudado, o setor alimentício ganhou 5,5 pp, seguido pela confecção de artigos do vestuário e fabricação de outros equipamentos de transporte. Dois setores que se destacam negativamente são o de móveis e têxteis que perdem participação, mas mantém suas posições de destaque na distribuição do emprego industrial.

\begin{tabular}{|c|c|c|c|c|c|c|}
\hline \multicolumn{2}{|c|}{ Tabela 2.18 - Distribuição percentual empregos industriais por setor - Microrregião Serrana (2003/2008/2014) } \\
\hline Setores & $\mathbf{2} 2003$ & $\mathbf{2 0 0 8}$ & $\mathbf{2 0 1 4}$ & Variação (pp) & Variação (pp) & Variação (pp) \\
\cline { 5 - 8 } & & & & $\mathbf{2 0 0 3 / 2 0 0 8}$ & $\mathbf{2 0 0 8 / 2 0 1 4}$ & $\mathbf{2 0 0 3 / 2 0 1 4}$ \\
\hline 18:Confec. de Art. do Vestuário & 21,7 & $\mathbf{2 8 , 1}$ & $\mathbf{2 5 , 8}$ & 6,3 & $-2,2$ & 4,1 \\
\hline 15:Fabr. Produtos Alimentícios & 14,6 & 18,2 & 20,0 & 3,6 & 1,9 & 5,5 \\
\hline 36:Fabr. de Móveis e Ind. Diversas & 13,8 & 7,3 & 7,7 & $-6,5$ & 0,5 & $-6,0$ \\
\hline 35:Fabr. de Outros Equip. Transp & 3,7 & 5,0 & 7,6 & 1,3 & 2,6 & 3,9 \\
\hline 17:Fabr. de Produtos Têxteis & 12,1 & 8,1 & 7,5 & $-4,0$ & $-0,7$ & $-4,7$ \\
\hline 25:Fabr. Art. de Borracha e Plást. & 4,8 & 7,7 & 6,3 & 2,8 & $-1,3$ & 1,5 \\
\hline 28:Fabr. de Produtos de Metal Exc. Máq. e Equip. & 5,1 & 4,1 & 5,2 & $-1,0$ & 1,1 & 0,1 \\
\hline 33:Fabr. de Equip. Médico-hospit. & 5,1 & 3,9 & 4,5 & $-1,2$ & 0,6 & $-0,6$ \\
\hline 22:Edição, Impressão e Reprodução de Gravações & 4,9 & 4,7 & 4,1 & $-0,2$ & $-0,6$ & $-0,7$ \\
\hline 24:Fabr. de Produtos Químicos & 3,3 & 3,5 & 2,5 & 0,2 & $-1,0$ & $-0,8$ \\
\hline 29:Fabr. de Máquinas e Equip. & 1,6 & 2,7 & 2,3 & 1,1 & $-0,4$ & 0,7 \\
\hline 21:Fabr. de Celulose e Papel & 3,3 & 1,7 & 1,7 & $-1,6$ & 0,1 & $-1,5$ \\
\hline 20:Fabr. de Produtos de Madeira & 1,1 & 1,3 & 1,2 & 0,2 & $-0,1$ & 0,1 \\
\hline 19:Prep. Couros e Art. de Calçados & 0,7 & 0,5 & 0,4 & $-0,2$ & $-0,1$ & $-0,3$ \\
\hline Demais setores & 1,7 & 1,8 & 1,6 & 0,0 & $-0,2$ & $-0,2$ \\
\hline
\end{tabular}

Fonte: Elaboração própria do autor (RAIS) 
$\mathrm{Na}$ distribuição da massa salarial da microrregião observamos a mesma dinâmica encontrada para o emprego. A principal diferença é o setor de fabricação de outros equipamentos de transporte que tem posição de destaque na massa de salários da região Serrana, em razão da existência de uma planta industrial da GE para manutenção de motores de aviões em Petrópolis. Os demais setores importantes na massa de salários são os mesmos do emprego.

\begin{tabular}{|c|c|c|c|c|c|c|}
\hline Tabela 2.19 - Distribuição percentual Massa salarial por setor - Microrregião Serrana (2003/2008/2014) \\
\hline Setores & $\mathbf{2 0 0 3}$ & $\mathbf{2} 2008$ & \multirow{2}{*}{$\mathbf{2 0 1 4}$} & Variação (pp) & Variação (pp) & Variação (pp) \\
\cline { 5 - 8 } & & & $\mathbf{2 0 0 3 / 2 0 0 8}$ & $\mathbf{2 0 0 8 / 2 0 1 4}$ & $\mathbf{2 0 0 3 / 2 0 1 4}$ \\
\hline 15:Fabr. Produtos Alimentícios & 10,8 & 17,6 & $\mathbf{2 2 , 1}$ & 6,9 & $\mathbf{4 , 5}$ & 11,4 \\
\hline 35:Fabr. de Outros Equip. Transp & 15,9 & 15,4 & 18,2 & $-0,5$ & 2,8 & 2,3 \\
\hline 18:Confec. de Art. do Vestuário & 11,5 & 15,3 & 15,2 & 3,8 & 0,0 & 3,7 \\
\hline 17:Fabr. de Produtos Têxteis & 12,6 & 7,8 & 6,8 & $-4,8$ & $-1,1$ & $-5,8$ \\
\hline 33:Fabr. de Equip. Médico-hospit. & 8,4 & 5,8 & 6,0 & $-2,6$ & 0,2 & $-2,4$ \\
\hline 28:Fabr. de Produtos de Metal Exc. Máq. e Equip. & 7,3 & 6,0 & 5,8 & $-1,3$ & $-0,2$ & $-1,5$ \\
\hline 25:Fabr. Art. de Borracha e Plást. & 5,1 & 6,9 & 5,6 & 1,8 & $-1,2$ & 0,6 \\
\hline 36:Fabr. de Móveis e Ind. Diversas & 10,3 & 4,8 & 5,3 & $-5,5$ & 0,5 & $-5,1$ \\
\hline 22:Edição, Impressão e Reprodução de Gravações & 5,1 & 4,4 & 3,7 & $-0,7$ & $-0,7$ & $-1,4$ \\
\hline 29:Fabr. de Máquinas e Equip. & 2,2 & 3,8 & 3,2 & 1,6 & $-0,6$ & 1,1 \\
\hline 24:Fabr. de Produtos Químicos & 4,5 & 7,3 & 3,1 & 2,7 & $-4,2$ & $-1,5$ \\
\hline 21:Fabr. de Celulose e Papel & 2,0 & 1,1 & 1,3 & $-0,9$ & 0,2 & $-0,7$ \\
\hline 26:Fabr. de Produtos de Minerais Não-metálicos & 1,9 & 0,9 & 1,0 & $-0,9$ & 0,1 & $-0,9$ \\
\hline 20:Fabr. de Produtos de Madeira & 0,8 & 0,9 & 0,9 & 0,1 & 0,0 & 0,1 \\
\hline 19:Prep. Couros e Art. de Calçados & 0,4 & 0,3 & 0,2 & $-0,1$ & $-0,1$ & $-0,2$ \\
\hline Demais setores & 1,3 & 1,6 & 1,5 & 0,4 & $-0,1$ & 0,2 \\
\hline
\end{tabular}

Fonte: Elaboração própria do autor (RAIS)

A distribuição de estabelecimento não se modifica durante o período, mantendo a concentração nos setores têxteis, confecções, alimentício e moveleiro. Esses quatro setores representam $66 \%$ de todos os estabelecimentos industriais da região Serrana. O salário médio na microrregião obteve ganhos reais em todos os setores, exceto na fabricação de outros equipamentos de transporte, que perdeu $19,5 \%$ no período. Outro destaque foi a fabricação de produtos alimentícios, que teve ganho de 115\% entre 2003 e 2014.

Tabela 2.20 - Distribuição percentual estabelecimentos industriais por setor - Microrregião Serrana (2003/2008/2014)

\begin{tabular}{|c|c|c|c|c|c|c|}
\hline Setores & \multirow{2}{*}{$\mathbf{2 0 0 3}$} & $\mathbf{2 0 0 8}$ & \multirow{2}{*}{$\mathbf{2 0 1 4}$} & Variação (pp) & Variação (pp) & Variação (pp) \\
\cline { 5 - 7 } & & & $\mathbf{2 0 0 3 / 2 0 0 8}$ & $\mathbf{2 0 0 8 / 2 0 1 4}$ & $\mathbf{2 0 0 3 / 2 0 1 4}$ \\
\hline 18:Confec. de Art. do Vestuário & 33,6 & 34,6 & 36,2 & 1,0 & 1,6 & 2,6 \\
\hline 15:Fabr. Produtos Alimentícios & 12,6 & 17,1 & 13,2 & 4,5 & $-3,9$ & 0,6 \\
\hline 36:Fabr. de Móveis e Ind. Diversas & 14,1 & 10,4 & 11,1 & $-3,7$ & 0,7 & $-3,0$ \\
\hline 28:Fabr. de Produtos de Metal Exc. Máq. e Equip. & 5,7 & 5,5 & 6,8 & $-0,3$ & 1,4 & 1,1 \\
\hline 22:Edição, Impressão e Reprodução de Gravações & 4,8 & 5,9 & 6,1 & 1,2 & 0,2 & 1,3 \\
\hline 17:Fabr. de Produtos Têxteis & 5,7 & 6,2 & 5,4 & 0,5 & $-0,8$ & $-0,3$ \\
\hline 25:Fabr. Art. de Borracha e Plást. & 5,6 & 5,4 & 4,2 & $-0,2$ & $-1,1$ & $-1,4$ \\
\hline 26:Fabr. de Produtos de Minerais Não-metálicos & 4,3 & 3,5 & 3,6 & $-0,9$ & 0,1 & $-0,8$ \\
\hline 29:Fabr. de Máquinas e Equip. & 2,1 & 2,4 & 3,2 & 0,2 & 0,9 & 1,1 \\
\hline 20:Fabr. de Produtos de Madeira & 3,1 & 2,7 & 2,6 & $-0,3$ & $-0,2$ & $-0,5$ \\
\hline 33:Fabr. de Equip. Médico-hospit. & 0,7 & 1,0 & 1,7 & 0,3 & 0,7 & 0,9 \\
\hline 24:Fabr. de Produtos Químicos & 1,4 & 0,5 & 0,7 & $-0,8$ & 0,2 & $-0,6$ \\
\hline 19:Prep. Couros e Art. de Calçados & 1,1 & 0,8 & 0,7 & $-0,2$ & $-0,2$ & $-0,4$ \\
\hline 21:Fabr. de Celulose e Papel & 1,1 & 0,9 & 0,6 & $-0,1$ & $-0,3$ & $-0,5$ \\
\hline 35:Fabr. de Outros Equip. Transp & 0,3 & 0,3 & 0,3 & 0,0 & 0,1 & 0,0 \\
\hline Demais setores & 3,8 & 2,8 & 3,5 & $-1,0$ & 0,7 & $-0,3$ \\
\hline
\end{tabular}

Fonte: Elaboração própria do autor (RAIS) 
Quando analisamos o índice de concentração HHI para a região Serrana, observamos uma elevação dos números em todas as variáveis. Isso se deve principalmente ao setor de Fabricação de produtos do vestuário, que se apresenta como um dos principais setores da microrregião e aumentou sua participação em todas as variáveis. Esse movimento setorial elevou o $\mathrm{HHI}$ para emprego, estabelecimento e massa salarial, apontando para a redução da diversificação setorial na região Serrana.

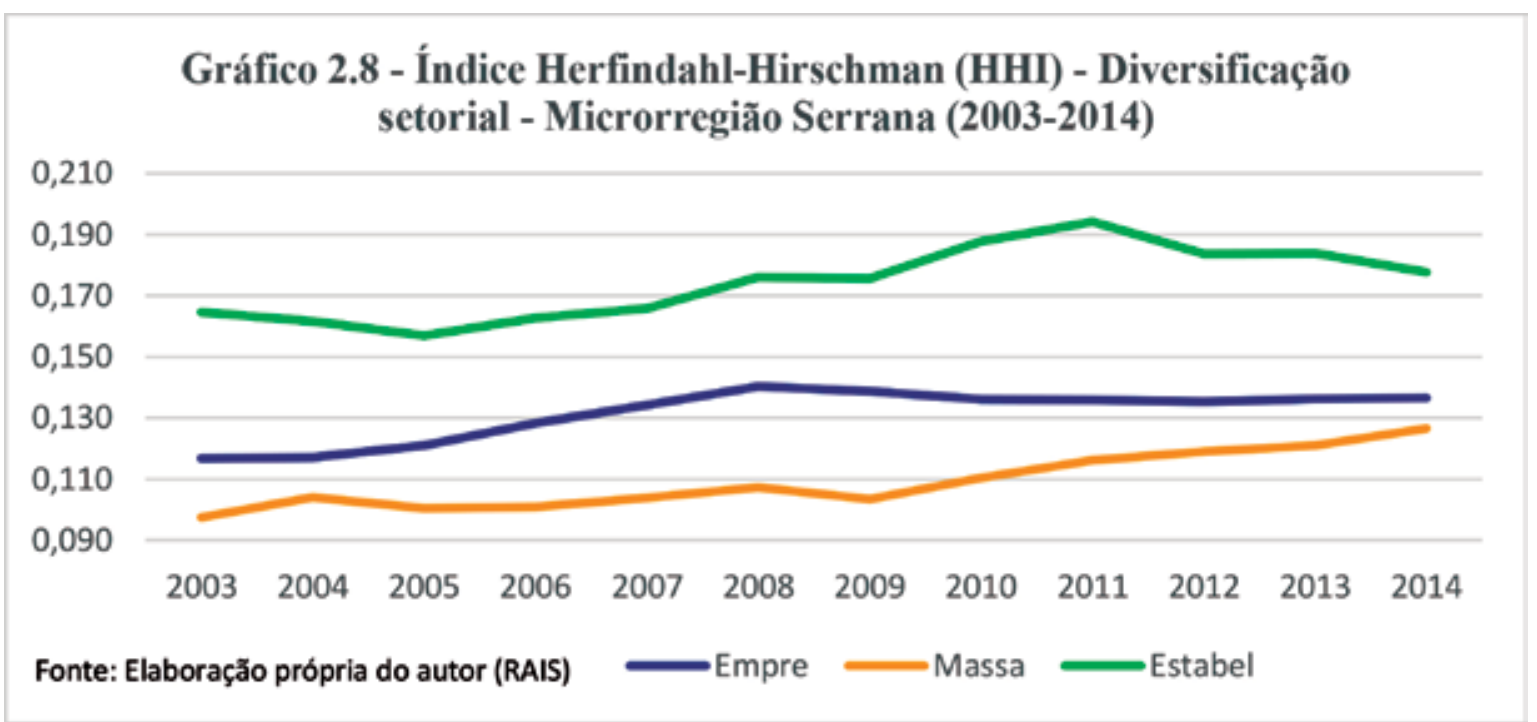

Finalizando, esta seção mostrou que o estado do Rio de Janeiro apresenta sinais de concentração nos setores ligados ao petróleo, mas essa dinâmica industrial é diferenciada dependendo da microrregião considerada, não havendo um padrão único para o cenário da indústria em todas as regiões do estado. Ao analisar as principais microrregiões do Rio de Janeiro concluímos que cada uma delas se especializou em determinados setores e mantiveram essa dinâmica durante o período analisado, em alguns casos aumentando e em outros reduzindo a diversificação setorial. As cadeias produtivas mostraram seu papel. O caso do setor de máquinas e equipamentos ligado ao setor petroleiro em Macaé e ao setor automobilístico que se instalou no Vale do Paraíba Fluminense é um bom exemplo de seu funcionamento.

\section{Considerações Finais}

Durante o século XX o setor industrial se consolidou como um importante determinante para o crescimento econômico e desenvolvimento do Brasil. Os primeiros movimentos da indústria no país, tiveram como destino as regiões metropolitanas de São Paulo e do Rio de Janeiro.

A caminhada da indústria em direção ao interior e às regiões mais afastadas dos grandes centros se intensificou no final do século XX através da expansão do mercado interno e de incentivos oferecidos regionalmente. Esse fenômeno, estudado por diversos autores citados nesse trabalho, consegue explicar parte do crescimento industrial ocorrido no período aqui estudado.

O foco desse trabalho foi o estado do Rio de Janeiro, região em que há carência de estudos recentes sobre a indústria. Os resultados encontrados para os processos de desconcentração regional e diversificação setorial da indústria no estado são diferenciados, dependendo em alguns casos das variáveis analisadas.

O estado do Rio de Janeiro passou por grandes transformações na indústria nas últimas décadas. O desenvolvimento dos setores de extração e refino de petróleo modificou a distribuição regional da indústria fluminense. A região metropolitana continuou sendo o 
principal centro produtivo, com setores bem distribuídos e de maior valor agregado. Já a microrregião de Macaé se tornou um importante polo industrial no estado, principalmente quando considerada a variável massa salarial, devido aos altos salários pagos pela indústria petroleira. Outras microrregiões importantes do estado, como a Serrana e o Vale do Paraíba Fluminense, mantiveram posições de destaque na distribuição geográfica industrial.

No geral, ocorreu desconcentração entre as microrregiões do estado do Rio de Janeiro, mas é importante salientar que o nível de concentração ainda permanece muito elevado, principalmente para a massa salarial que é diretamente afetada pelo setor de petróleo.

O estado do Rio de Janeiro apresenta resultado até certo ponto inconclusivo para a diversificação setorial na indústria, devido a diferentes movimentos para cada uma das variáveis. $\mathrm{O}$ índice $\mathrm{HHI}$ mostra concentração na massa salarial, estabilidade no número de estabelecimentos e diversificação setorial quando considerado o emprego na indústria.

O fortalecimento do setor do petróleo, atraiu uma importante cadeia produtiva para 0 estado. Algumas microrregiões fluminenses se desenvolveram e ganharam importantes setores da indústria entre 2003 e 2014. Os setores de máquinas e equipamentos e de equipamentos de transporte, tiveram expressivo crescimento. Outro fator importante no desenvolvimento da indústria estadual foram as isenções fiscais para o setor automotivo. A microrregião que mais se beneficiou foi a do Vale do Paraíba Fluminense, com a instalação de plantas produtivas no setor de fabricação e montagem de veículos automotores e reboques.

A principal mensagem passada pelo artigo é que os processos de desconcentração regional e diversificação setorial da indústria são complexos e demandam um estudo especializado para cada região e setor. No período analisado. o país se desconcentrou regionalmente. 0 parque industrial do Rio de Janeiro também apresentou desconcentração regional, apesar da manutenção de um alto índice de concentração industrial na análise geográfica. Já os dados de diversificação setorial no estado são ambíguos.

O crescimento da indústria nos últimos anos perdeu força por conta da atual crise econômica, mas é de suma importância identificar os determinantes e as consequências da dinâmica industrial no período estudado, para que em um novo ciclo de crescimento possamos aproveitar melhor as oportunidades de reduzir as desigualdades, a concentração regional e setorial, e permitir que os benefícios do setor industrial cheguem às mais diversas localidades do país e do próprio estado do Rio de Janeiro. 


\section{Referências bibliográficas}

ARDISSONE, M. S. Mudança na distribuição espacial das atividades industriais por microrregião no período 1996/2005. 2009. 410 f. Tese (Doutorado em Ciências Econômicas) - Instituto de Economia, Universidade Federal do Rio de Janeiro, Rio de Janeiro, 2009.

AZEVEDO, P. F., TONETO JÚNIOR, R. Relocalização do emprego industrial formal no Brasil na década de 90. Pesquisa e Planejamento Econômico, v. 31, n. 1, abr. 2001.

AZZONI, C. R. Sobre a necessidade da política regional. In: KON, A. Unidade e fragmentação: A questão regional no Brasil. São Paulo: Perspectiva, 2002.

DINIZ, C. C. Desenvolvimento poligonal no Brasil: Nem desconcentração, nem contínua polarização. Nova Economia, v. 3, n. 1, set. 1993.

DINIZ, C. C.; CROCCO, M. A. Reestruturação econômica e impacto regional: O novo mapa da indústria brasileira. Nova Economia, v. 6, n. 1, jul. 1996.

EGLER, C. A. G.; DOMINGUEZ, M. T.; REGATO, A. N. Dinâmica Territorial e a Estruturação Espacial do Estado do Rio de Janeiro. Cadernos do Desenvolvimento Fluminense, Rio de Janeiro, n. 8, jul. 2015

LACERDA, H. S. R. Desconcentração Regional e Diversificação Setorial da Indústria no Estado do Rio de Janeiro entre 2003 e 2014. Monografia de graduação em Ciências Econômicas. Instituto de Economia, Universidade Federal do Rio de Janeiro, jan. 2017.

LACERDA, H. S. R. e SABOIA, J., Desconcentração regional e diversificação setorial da indústria no estado do Rio de Janeiro - 2003/2014. Texto para Discussão 14. Instituto de Economia, Universidade Federal do Rio de Janeiro, 2017.

LEMOS, M. B. et al. A organização territorial da indústria no Brasil. In: DE NEGRI, J. A.; SALERNO, M. S. Inovações, padrões tecnológicos e desempenho das firmas industriais brasileiras. IPEA. Rio de Janeiro: IPEA, 2005.

MARCELINO, I.S., BRITTO, J., CASSIOLATO, J.E. Especialização e dinamismo inovativo da indústria fluminense: desafios e potencialidades para o desenvolvimento regional. Uma agenda para o Rio de Janeiro, v.1, 2015

MEDEIROS JÚNIOR, H. Desconcentração econômica e atratividade regional no estado do Rio de Janeiro entre 2000 e 2010. Cadernos do Desenvolvimento Fluminense, Rio de Janeiro, n. 1, fev. 2013

MEDEIROS JÚNIOR, H. Desenvolvimento regional e desigualdade sócio espacial fluminense nos anos 2010. Cadernos do Desenvolvimento Fluminense, Rio de Janeiro, n.6, nov. 2014

MONTOYA, M.A. O agronegócio no Mercosul: Dimensão Econômica, Desenvolvimento Industrial e Interdependência Estrutural na Argentina, Brasil, Chile e Uruguai. RBE Rio de Janeiro out/dez 2002.

NEGRI, B. Concentração e desconcentração industrial em São Paulo (1880-1990). 1994. 280 f. Tese (Doutorado em Economia) - Universidade Estadual de Campinas, Campinas, 1994.

OLIVEIRA JÚNIOR, M. Aglomeração espacial e eficiência industrial: Um estudo a partir da evolução da produtividade nos municípios brasileiros de 1970 a 1996. 2006. Tese (Doutorado em Ciências Econômicas) - Instituto de Economia, Universidade Federal do Rio de Janeiro, Rio de Janeiro, 2006. 
PACHECO, C. A. Novos padrões de localização industrial? Tendências recentes dos indicadores da produção e do investimento industrial. Texto para Discussão, n. 633. IPEA, Brasília, mar. 1999.

PEREIRA, F. M.; LEMOS, M. B. Cidades médias brasileiras: Características e dinâmicas urbano-industriais. Pesquisa e Planejamento Econômico, v. 33, n. 1, abr. 2003.

RAMOS, L.; FERREIRA, V. Geração de empregos e realocação espacial do mercado de trabalho brasileiro - 1992-2002. Pesquisa e Planejamento Econômico, v. 35, n. 1, abr. 2005.

SABOIA, J. Descentralização industrial no Brasil nos anos 90: Um enfoque regional. Pesquisa e Planejamento Econômico, v. 30, n. 1, abr. 2000.

SABOIA, J. Descentralização industrial no Brasil na década de noventa: Um processo dinâmico e diferenciado regionalmente. Nova Economia, v. 11, n. 2, dez. 2001.

SABOIA, J. A indústria brasileira no Nordeste e as desigualdades inter e intra regionais. Econômica, v. 6, n. 1, jun. 2004.

SABOIA, J. - A continuação do processo de desconcentração regional da indústria brasileira nos anos 2000. Nova Economia, v.23, n. 2, maio-agosto de 2013.

SILVA, R. D. (2009) Estrutura Industrial e Desenvolvimento Regional no Estado do Rio de Janeiro (1990-2008). Tese de Doutoramento. Campinas: IE-Unicamp.

SOBRAL, B.L.B. Limites ao Desenvolvimento do Estado do Rio de Janeiro: Aspectos Estruturais de seu Processo de Industrialização no período recente. Econômica, Rio de Janeiro, v. 11, n. 2, p. 133-154, dezembro 2009.

SOBRAL, B.L.B. A Falácia da "inflexão econômica positiva": algumas características da desindustrialização fluminense e do "vazio produtivo" em sua periferia metropolitana.

Cadernos do Desenvolvimento Fluminense, Rio de Janeiro, n.10, mar./jun. 2016.

SUZIGAN, W. et al. Aglomerações industriais no Estado de São Paulo. Economia Aplicada, v.5, n.4, p.695-717, out./dez. 2001. 